\title{
Dinosaur energetics: setting the bounds on feasible physiologies and ecologies
}

\author{
Andrew Clarke ${ }^{1,2, *}$
}

1. British Antarctic Survey, High Cross, Madingley Road, Cambridge CB3 0ET, U.K.

2. School of Environmental Sciences, University of East Anglia, Norwich NR4 7TJ, U.K.

*Corresponding author; e-mail: accl@bas.ac.uk

Article type: Synthesis

Keywords: dinosaur, energetics, growth, metabolism, migration, size, temperature.

Accepted for publication by American Naturalist on 29 March 2013 and published electronically on 19 July 2013.

American Naturalist 182 (3): 283-297, 2013; doi: 10.1086/671259). See:

http://www.jstor.org/stable/10.1086/670340.

\begin{abstract}
The metabolic status of dinosaurs has long been debated but remains unresolved as no consistent picture has yet emerged from a range of anatomical and isotopic evidence. Quantitative analysis of dinosaur energetics, based on general principles applicable to all vertebrates, shows that many features of dinosaur lifestyle are compatible with a physiology similar to that of extant lizards, scaled up to dinosaur body masses and temperatures. Sufficient metabolic scope would have been available to support observed dinosaur growth rates and allow considerable locomotor activity, perhaps even migration. Since at least one dinosaur lineage evolved true endothermy, this analysis emphasises that there was no single dinosaur physiology. Many small theropods were insulated with feathers and appear to have been partial or full endotherms. Uninsulated small taxa, and all juveniles, would presumably have been ectothermic, with consequent diurnal and seasonal variations in body temperature. In larger taxa inertial homeothermy would have resulted in warm and stable body temperatures, but with a basal metabolism significantly below that of living mammals or birds of the same size. It would appear that dinosaurs exhibited a range of metabolic levels to match the broad spectrum of ecological niches they occupied.
\end{abstract}




\title{
Introduction
}

For many years it was believed that dinosaurs had an ectothermic metabolism, akin to that of living reptiles. The first challenge to this assumption came from the discovery of the theropod Deinonychus, whose anatomy suggested strongly that it was an active predator and whose lifestyle may have required a more endotherm-like metabolism (Ostrom 1969, 1970).

We now recognise that endothermy evolved in the theropod/bird lineage, possibly quite early. Whilst other dinosaurs appear resolutely reptilian in their anatomy, and by inference their physiology, it has been suggested that in the larger non-avian dinosaurs some form of intermediate metabolism (that is somewhere between ectothermy and full endothermy) must have been necessary to power their inferred ecology (Reid 1997a; Sander and Clauss 2008; Sander et al. 2011). The precise level of this intermediate metabolism has, however, not been quantified. Others have suggested that sauropods were fully endothermic, at least when young (Pierson 2009).

Whilst isotopic evidence points to a high body temperature in sauropods (Eagle et al. 2011), this of itself does not indicate the level of metabolism. Modelling of heat flow has shown clearly that larger dinosaurs would have maintained stable, and often high, temperatures from thermal inertia alone (Spotila et al. 1973; Spotila 1980; O'Connor and Dodson 1999; Seebacher 2003). Isotopic data have confirmed a relatively uniform body temperature in many larger dinosaurs (Barrick et al. 1996, 1997) but thermal inertia means that it is not necessary to hypothesise an elevated metabolism to explain these data (though neither is an elevated metabolism ruled out). Whilst the influence of large size on thermal inertia has attracted considerable attention, many dinosaurs were small as adults and all were small as hatchlings or juveniles. In addition some dinosaurs lived in highly seasonal environments, including at high latitudes (Bell and Snively 2008; Chinsamy et al. 2011). All of these would have experienced daily and seasonal variations in body temperature, though presumably moderated by behavioural thermoregulation as in living reptiles today.

One way to attempt to resolve the question of the metabolic status of dinosaurs is to take a quantitative approach and model their energetics (Sander et al. 2011). Constructing a thermodynamically rigorous, balanced energy budget allows us to define feasible boundary conditions for dinosaur energetics. These can then be compared with anatomical and isotopic data to constrain possible dinosaur physiology more objectively. Since we know that true endothermy evolved in at least one dinosaur lineage, parameterisation of the model with data from extant mammals and birds can define a likely upper boundary to dinosaur metabolic rate. The lower boundary can be explored by assuming a physiology resembling that of living reptiles.

The central question tackled in this synthesis is: could dinosaurs have worked simply as large reptiles? If the answer is yes, then the case for endothermy or an intermediate metabolic status in some lineages is weakened. If the answer is no, the model can be used to explore constraints on the nature of dinosaur metabolism.

\section{Modelling dinosaur energetics}

\author{
Choice of model
}


Although the focus of this synthesis is dinosaurs, a thermodynamically rigorous model of energetics should have a structure that is applicable to any vertebrate. The traditional model for vertebrate energetics has long been the balanced energy budget developed during the International Biological Program (IBP) (Petrusewicz and Macfadyen 1970). In recent years, however, two quite different new approaches have been developed, namely Dynamic Energy Budget (DEB) theory and the Metabolic Theory of Ecology (MTE).

The DEB is a model that tracks the flow of energy and materials through an individual organism throughout its life-cycle from zygote to adult (Kooijman 1993, 2000, 2009). A DEB model, however, requires a number parameters that are impossible to estimate for extinct organisms; whilst DEB models have proved valuable for living taxa (Kearney 2012), this difficulty makes them problematic for exploring dinosaur energetics.

The MTE is centred on a single master equation which captures energy flow in terms of body mass and body temperature. The MTE predicts a scaling exponent of 0.75 for the mass dependency, and posits a Boltzmann temperature sensitivity with an activation energy of $0.65 \mathrm{eV}$ (West et al. 1997; Gillooly et al. 2001; Brown et al. 2004). The model includes parameters that have to be fitted empirically for a given group of organisms, typically using data for basal or resting metabolic rate. The central equation of the MTE itself does not allow estimation of the energy utilised in important ecological processes such as growth, reproduction or locomotion, although a number of extensions to the MTE do so (West et al. 2001; Moses et al. 2008; Hou et al. 2008).

The model used here is therefore the IBP balanced energy budget, modified to make explicit the heterogeneous nature of respiratory demand (Clarke 1987). For details of model selection see the electronic supplementary material (ESM).

\section{The balanced energy budget model}

An organism is an open thermodynamic system, continually exchanging both energy and materials with its environment. The balanced energy budget is based on the premise that when averaged over some defined time period, the energy an organism acquires from its environment matches exactly the energy dissipated in respiration, lost in excretion or sequestered in new tissue. Thus:

$$
\mathrm{C}=\Sigma \mathrm{R}+\Sigma \mathrm{P}+\Sigma \mathrm{E}+\mathrm{F}
$$

where $\mathrm{C}$ is consumption, $\Sigma \mathrm{R}$ respiratory losses, $\Sigma \mathrm{P}$ production (somatic tissue and gonads), $\Sigma$ E excretory losses and $\mathrm{F}$ the unabsorbed energy voided as faeces. The time period needs to be sufficient to integrate short term variations in energy flow (see ESM), and is typically one day.

\section{Parameterising the model}

The state variables in the model were body mass $(\mathrm{Mb}, \mathrm{g})$ and body temperature $\left(\mathrm{Tb},{ }^{\circ} \mathrm{C}\right)$; parameterisation of the model thus involved statistical fits of empirical data to $\mathrm{Mb}$ and $\mathrm{Tb}$. These data came from ecophysiological studies of extant reptiles, mammals and birds. The parameterisation is outlined below, and described in detail in the ESM. 
Most difficulty with parameterisation surrounds the respiration term $(\Sigma \mathrm{R})$. Typically respiration dominates the energy budget, though its importance differs between endotherms and ectotherms. The problem, both conceptual and practical, is that $\Sigma \mathrm{R}$ represents the dissipation of energy through a variety of different processes which may compete for resources.

Basal (maintenance) metabolism, BMR, is usually estimated by a measure of resting metabolic rate. BMR typically exhibits a power law relationship with body mass $(\mathrm{Mb})$ and an exponential dependence on body temperature $(\mathrm{Tb})$. Inclusion of body temperature is important, as its influence on BMR is significant. This temperature dependence has traditionally been ignored in analyses of mammalian metabolism, presumably on the assumption that in mammals $\mathrm{Tb}$ exhibits a narrow range of values. In fact mammals show a range of $\mathrm{Tb}$ values $>10 \mathrm{~K}$ (Clarke and Rothery 2008) and the effect of $\mathrm{Tb}$ on endotherm metabolism is statistically and physiologically significant (Angilletta et al. 2010; Clarke et al. 2010).

The upper bound for dinosaur BMR can be defined by the relationship for larger mammals (that is, mammals with $\mathrm{Mb}>150 \mathrm{~g}$, where the scaling of BMR is effectively linear: Clarke et al. 2010). The lower bound was estimated with data from extant reptiles. Analysis with a General Linear Model (GLM) indicated a highly significant difference in scaling between snakes (Ophidia) and lizards (Lacertilia) (see ESM). On the assumption that lizards are a better ecological model for dinosaurs than snakes, the scaling relationship for lizards was used in the analysis. Body temperatures were assumed to be $37.5^{\circ} \mathrm{C}$ for endotherms, this being close to the observed median $\mathrm{Tb}$ for extant mammals (Clarke and Rothery 2008). Reptilian relationships were estimated for $\mathrm{Tb}$ values of $15^{\circ} \mathrm{C}, 25^{\circ} \mathrm{C}$ and $35^{\circ} \mathrm{C}$.

A

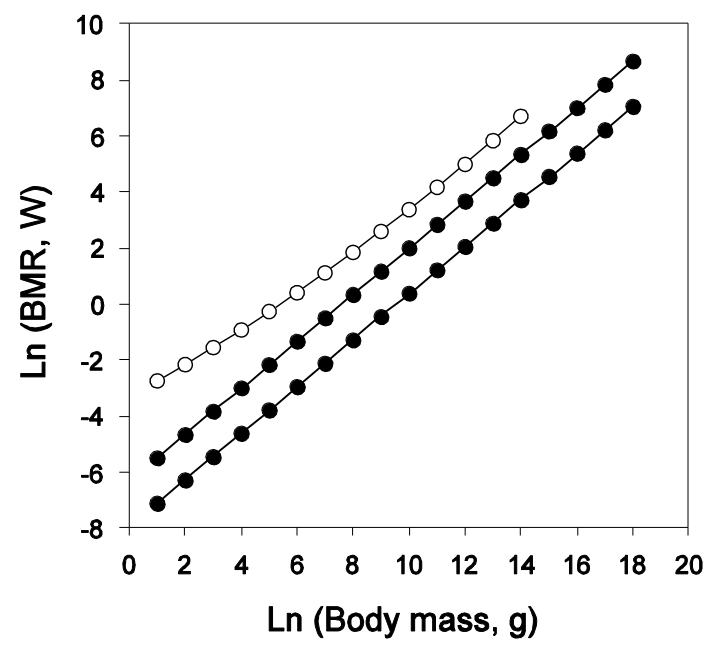

B

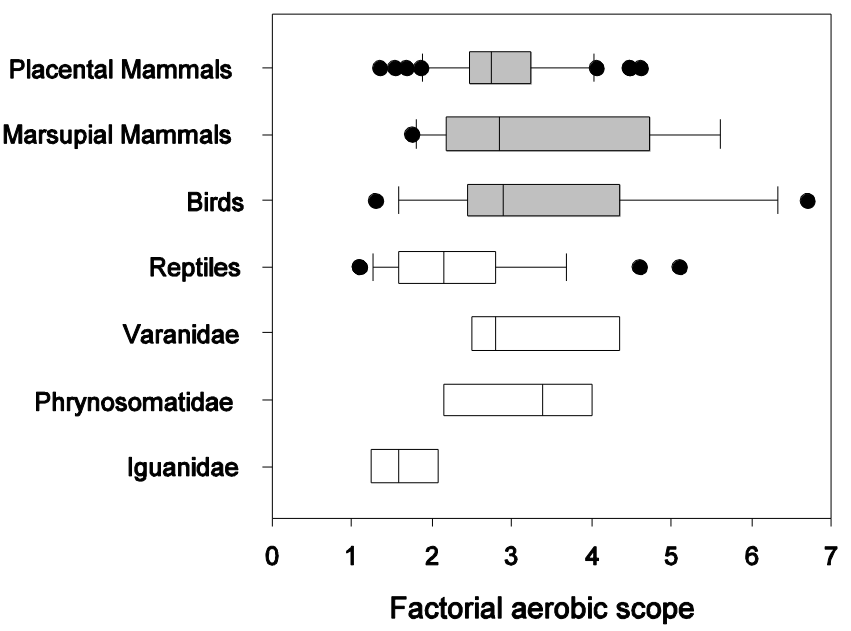

Figure 1. A. Basal metabolic rate (BMR, W) as a function of body mass (g) in reptiles (black symbols), extrapolated to the body mass values of dinosaurs (plotted range $3 \mathrm{~g}$ to 65 tonnes), and compared with mammals (open symbols, plotted range $3 \mathrm{~g}$ to 1.2 tonnes). The reptile relationships are for $\mathrm{Tb}$ of $15^{\circ} \mathrm{C}$ (lower) and $35^{\circ} \mathrm{C}$ (higher), and the mammal relationship for $37.5^{\circ} \mathrm{C}$. B. Boxplots of factorial aerobic scope (FMR/BMR) for terrestrial vertebrates. Data for endotherms are shown in grey, and ectotherms in white. Plots show median with 25th and 75th percentiles (box), together with 10th and 90th percentiles (whiskers) and individual outliers (dots). Data from Nagy (2005) and Clarke and Pörtner (2010). 
In figure $1 \mathrm{~A}$ the estimated BMR for dinosaurs with body temperatures of $15^{\circ} \mathrm{C}$ and $35^{\circ} \mathrm{C}$ is compared with data for extant mammals. These two temperatures were selected to represent a cool reptile and a warm reptile. For an individual of body mass $10-20 \mathrm{~kg}$, mean mammalian BMR ( $\mathrm{Tb} 37.5^{\circ} \mathrm{C}$ ) exceeds the estimated BMR for dinosaurs by a factor of $\sim 20$ (dinosaur $\mathrm{Tb} 15^{\circ} \mathrm{C}$ ) or $\sim 4$ (dinosaur $\mathrm{Tb} 35^{\circ} \mathrm{C}$ ). The BMR of a warm reptile is still well below that of an endotherm.

BMR is essentially the cost of maintaining a body of a given size and temperature. The processes comprising BMR are many and varied (Milligan and Summers 1986; Blaxter 1989; Hulbert and Else 2000, 2004), but the critical point is that energy dissipated in BMR does not contribute to processes such as growth, reproduction or locomotor activity. These, together with all the routine day to day activities of the organism, are fuelled by the metabolic scope, which is the respiration additional to BMR.

BMR and the metabolic scope together comprise the routine total metabolic rate of the organism, $\Sigma \mathrm{R}$ :

$$
\Sigma \mathrm{R}=\mathrm{BMR}+[\mathrm{Ra}+\mathrm{CoG}+\mathrm{Rm}]
$$

Here the processes fuelled from the metabolic scope are grouped within square brackets. Note that this is the routine (sustained) aerobic scope, which is lower than the maximum aerobic scope; the latter can be maintained only for short periods before exhaustion sets in. The major contributions to the routine metabolic scope are the cost of activity, Ra, which encompasses all the locomotor and behavioural costs of existence, the thermodynamic costs of growth (CoG), and the respiratory costs of all those non-basal metabolic processes involved in everyday existence, $\mathrm{Rm}$.

This routine metabolic rate, $\Sigma \mathrm{R}$, when averaged over time and under conditions when body mass remains constant (because energy intake and energy use are in balance), has been termed the sustained metabolic rate (Peterson et al. 1990; Hammond and Diamond 1997) or the mean daily energy expenditure (DEE). It is estimated by ecologists from the field metabolic rate (FMR), which is typically measured by isotope turnover (Nagy 2005). These various terms ( $\Sigma$ R, FMR, DEE, Routine Metabolic Rate) have differing conceptual bases, but ecologically they are broadly equivalent.

The second key measure for parameterising the model is thus FMR. We can then estimate factorial aerobic scope (FMR/BMR) and absolute metabolic scope (FMR - BMR). FMR data are available for a range of mammals, birds and reptiles. Body temperature data are not available for few of these studies, as Tb is difficult to measure in a free-ranging vertebrate. Moreover $\mathrm{Tb}$ varies throughout the day depending on the level of activity and the thermal environment. Analysis of data for factorial metabolic scope (FMR/BMR) in living taxa shows that modern reptiles sustain a long-term routine metabolic rate whose factorial increase over resting metabolism overlaps extensively with that of endotherms (figure 1B). Placental mammals have a somewhat higher factorial scope than most reptiles, but this difference is small in absolute terms, and the data have to be treated with caution because of the lack of $\mathrm{Tb}$ data.

Within reptiles factorial scope varies significantly across lizard families (see ESM). These lineage-specific differences are associated with lifestyle, with field metabolic rate and factorial aerobic scope higher in widely-foraging species such as varanids than in more 
sedentary sit-and-wait predators; these differences were statistically significant under both conventional covariance analysis and using independent contrasts to control for the effects of phylogeny (Etheridge \& Witt, 1993; Brown \& Nagy, 2007). For calculating metabolic scope, the all-reptile factorial aerobic scope of 2.5 was assumed for herbivores, and a varanid aerobic scope of 3.3 assumed for active carnivores.

\section{Growth rate}

Determining dinosaur growth rate requires knowledge of mass at age. Unfortunately neither mass nor age is easy to estimate in dinosaurs. Most progress has been made with lines of arrested growth (LAGs) in bone sections to estimate age (Reid 1997b), coupled with allometric relationships between long-bone size and body mass established for extant mammals, birds and reptiles to estimate body mass. These data are then used to fit a growth model; the growth model used for dinosaurs is typically sigmoidal, where the growth rate is maximal at an intermediate size, below adult body mass (which is assumed to be asymptotic).

A

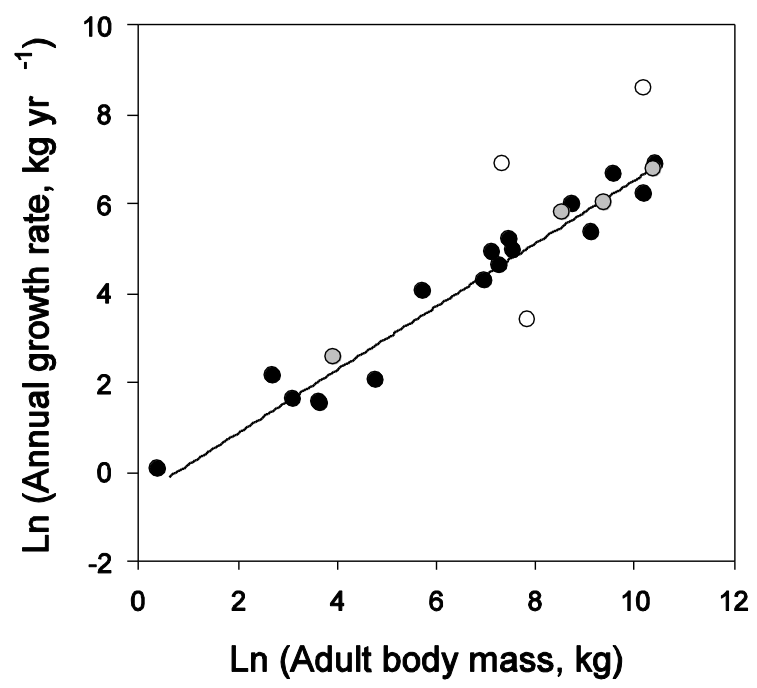

B

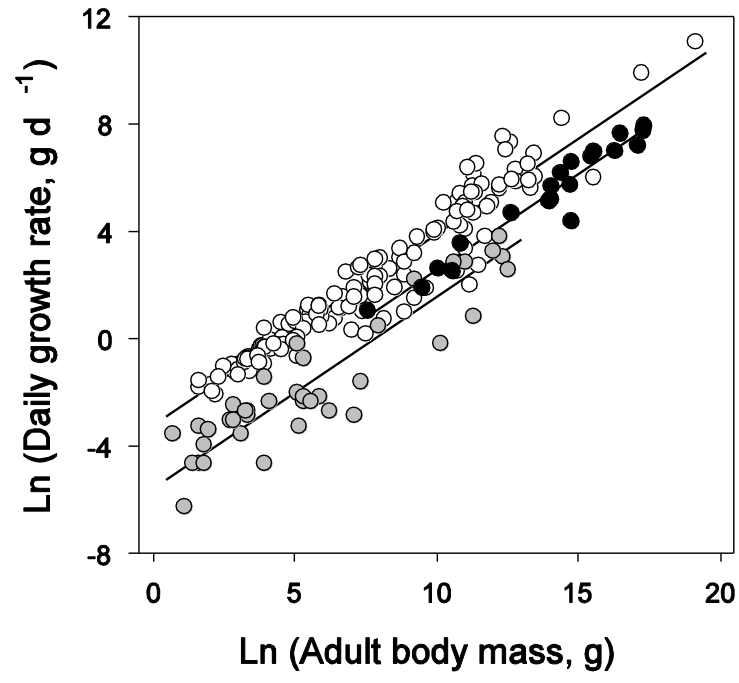

Figure 2. Growth rates in dinosaurs. A. Relationship between estimated maximum annual growth rate $\left(\mathrm{kg} \mathrm{y}^{-1}\right)$ in dinosaurs and adult (asymptotic) body mass (kg) (black symbols and fitted line). The scaling exponent is 0.75 (SE 0.07). Data for growth rate averaged over the lifespan shown for four taxa (grey symbols, not included in fitted relationship). Data for Apatasaurus and Maiasaura from Erickson et al. (2001) and Chasmosaurus from Lehman (2007) are shown as white symbols, and not included in the fitted relationship. B. Comparison of daily growth rate in mammals (white symbols), reptiles (grey symbols) and dinosaurs (black symbols). Reptile and mammal data are from Case (1978a); dinosaur data assume aseasonal growth. Lines show least-squares linear regressions fitted with a General Linear Model; the common slope is 0.71 (SE 0.02).

Growth rate data for dinosaurs were compiled from the literature (see ESM). For most taxa, maximum annual growth rate can be estimated for the point of inflection in the growth curve where growth rate is at its maximum. In four taxa, however, growth rate can only be estimated by averaging over the life cycle. The data suggest that annual growth rate increases with asymptotic body size, as would be expected (Figure 2A). There is no difference in the scaling between data for maximum annual growth rate (estimated for the point of inflection in the growth curve) and growth rate averaged over the entire life span (General Linear Model, GLM: $F_{2,17}=0.16, p=0.62$ ). Neither were there differences between Saurischia and 
Ornithischia (GLM, $\left.\mathrm{F}_{2,17}=0.2, \mathrm{p}=0.66\right)$, or between herbivores and carnivores $\left(\mathrm{GLM}, \mathrm{F}_{2,17}=\right.$ $0.25, \mathrm{p}=0.62)$.

Dinosaur growth rates may be compared with data for maximum daily growth rate in reptiles and mammals from the study by Case (1978a). To do so, dinosaur annual growth rates need to be converted to daily growth rates; this was done on the assumption that growth was either aseasonal (year-round) or seasonal and took place over half the year. This is somewhat arbitrary, though the existence of LAGs itself suggests a degree of seasonality in growth.

Analysis with a General Linear Model indicates that the scaling of growth rate with body mass in dinosaurs has a similar slope to that of mammals and reptiles (or at least that we cannot reject this hypothesis with the data available); this contrasts with the somewhat steeper relationship that is often depicted. The GLM does, however, indicate that dinosaurs had a higher maximum daily growth rate than living reptiles, but lower than in mammals (figure 2B). Mean daily growth rate in mammals exceeds that of reptiles by a factor of $\sim 10$, whilst dinosaurs exceed that of reptiles by a factor of $\sim 4$. However the precise value of these factors depends critically on assumptions concerning the seasonality of dinosaur growth; if dinosaur growth was highly seasonal then the factor could be as much as $\sim 8$.

These conclusions are qualitatively similar to those of Case (1978b), though this early study was based on growth data for only two dinosaur taxa. However comparisons across vertebrate classes are complicated by the very different ways in which growth rate was measured. Reptile growth is subject to marked individual and temporal variation; Case (1978a) therefore used the maximum short-term growth rate observed in captive reptiles. Typically this maximum growth rate corresponded to the growth exhibited by young hatchlings until they had achieved about $30 \%$ of total growth. For mammals growth rate was calculated over the period from 5\% adult body mass to $30-50 \%$ adult mass; over this period growth was often approximately linear (Case 1978a). The dinosaur data were derived from a life-time growth model based on LAGs in long bones.

These differences mean that quantitative comparisons must be treated with considerable caution. Nevertheless the differences in technique are unlikely to alter the qualitative conclusion, which is that dinosaurs exhibited a growth rate somewhat faster than living reptiles but slower than that of mammals. For the purposes of the dinosaur energetics model, the energy required for growth was calculated from the observed dinosaur growth rates (figure 2A). Daily growth was estimated on the assumption that dinosaurs grew for half the year (taken as 187 days for the Late Mesozoic), though the model estimate of total energy demand was relatively insensitive to this assumption (see ESM).

\section{Cost of growth}

The energy content of tissue can be either determined directly by calorimetry or estimated from its chemical composition. An energy content of $5.61 \mathrm{~kJ} \mathrm{~g}^{-1}$ was used in the model (see ESM for the derivation of this value). The energy content of tissue is, however, an incomplete measure of the energy required to grow or produce gonads. Tissue synthesis is not perfectly efficient and always incurs thermodynamic costs (the cost of growth, CoG). This overhead is seen as respiration and can be an important component of the metabolic scope. The cost of growth exhibits a fairly constant relationship to the energy invested in new tissue and the best estimate of this cost is $0.33 \mathrm{~J} \mathrm{~J}^{-1}$ (Parry 1983; Wieser 1994). In other 
words, the production of $100 \mathrm{~kJ}$ of new somatic tissue involves an additional respiratory cost overhead of $33 \mathrm{~kJ}$.

\section{Locomotor costs in dinosaurs}

The biomechanical cost of transport, that is the mass-specific cost of travelling unit distance, varies inversely with body mass. This relationship is mediated through the forces necessary to support the weight of the body, and the cost of transport is determined by a fundamental relationship with limb length (Pontzer 2007). In modelling energetics, the correlation between cost of transport and body mass is the most useful relationship, with the important caveat that the range of body masses in the empirical data exhibit only a small overlap with those of typical dinosaurs. A biomechanical model relating cost of transport to effective limb length has been used to estimate the cost of transport in dinosaurs (Pontzer et al. 2009), and the estimated costs for a range of dinosaurs were well fitted by an extrapolation of the relationship between cost of transport and body mass in extant terrestrial vertebrates. This relationship was used to estimate locomotor costs in dinosaurs (see ESM for further details).

\section{An energy budget for dinosaurs}

The model was parameterised initially for actively growing, sub-adult dinosaurs. This stage of the life cycle was chosen so that the energetics of growth could be explored; in adult dinosaurs growth has effectively ceased. The model was run for a range of values of $\mathrm{Mb}(10$ $\mathrm{g}$ to 65 tonnes) and $\mathrm{Tb}\left(15-40^{\circ} \mathrm{C}\right)$. Endothermic dinosaurs were modelled assuming a $\mathrm{Tb}$ ranging from 35 to $40^{\circ} \mathrm{C}$; respiration and factorial aerobic scope were parameterised with data for mammals. Ectothermic dinosaurs were modelled assuming a Tb ranging from 15 to $35^{\circ} \mathrm{C}$. Ectothermic herbivores and carnivores were assumed to have slightly different energetics. Carnivores were modelled as active predators, using energetic variables and relationships taken from varanid lizards; herbivores were assumed to be better approximated by the allreptile relationships. In both endotherm and ectotherm dinosaurs the absorption efficiency was assumed to be $50 \%$ in herbivores and $85 \%$ in carnivores (Weaver 1983; Beaupre et al. 1993; Lehman 2007).

A budget was then calculated using a time period of one day ( 24 hours). This time-period is intermediate between the measurement periods typical for basal metabolism (hours) and growth (days to years); it is also long enough to smooth short-term variations in total energy demand that characterise day to day existence. Full details of the budget are given in the ESM.

Since endothermy evolved in the lineage leading to birds, it is a reasonable assumption that endothermy defines the upper boundary to feasible dinosaur energetics. Although birds have long been known to have a higher Tb than mammals (Clarke and Rothery 2008), and hence a higher BMR, recent analyses have suggested that the underlying thermal physiology is similar in the two groups (Clarke et al. 2010). The BMR of an endothermic dinosaur can therefore be modelled by assuming a mammalian physiology with a $\mathrm{Tb}$ in the range $35-40^{\circ} \mathrm{C}$.

Two important questions in assessing the validity of an energy budget model are: is it internally consistent, and does it balance? Whilst the model was parameterised with growth data from dinosaurs and metabolic data from living reptiles (ectothermic dinosaurs) and 
mammals (endothermic dinosaurs), the balance and internal consistency are assessed using principles that apply to vertebrate energetic in general.

\section{Internal consistency}

The major boundary condition for internal consistency in the energy budget is set by the absolute metabolic scope, which must fuel the thermodynamic cost of growth, the cost of activity and all other non-locomotor costs. BMR and absolute metabolic scope together determine the level of daily energy expenditure (the FMR of a free-living dinosaur, were we able to measure it).

No organism uses all of its metabolic scope for a single activity, though in the very short term activities such as predator avoidance may monopolise available energy. The best guide as to how dinosaurs might have partitioned their metabolic scope comes from studies of lizards (Christian et al. 1997) which have suggested that $\sim 57 \%$ of their metabolic scope is used for locomotor activities (foraging, seeking mates, territorial defence), though the confidence limits on this estimate are wide. For varanids alone, the value was $\sim 75 \%$. A rounded alllizard value of $60 \%$ was used in the model for herbivores, and the varanid mean of $75 \%$ used for carnivores. This leaves $40 \%$ (herbivores) or $25 \%$ (carnivores) of the absolute metabolic scope to fuel the cost of growth and other non-locomotor metabolic costs.

A

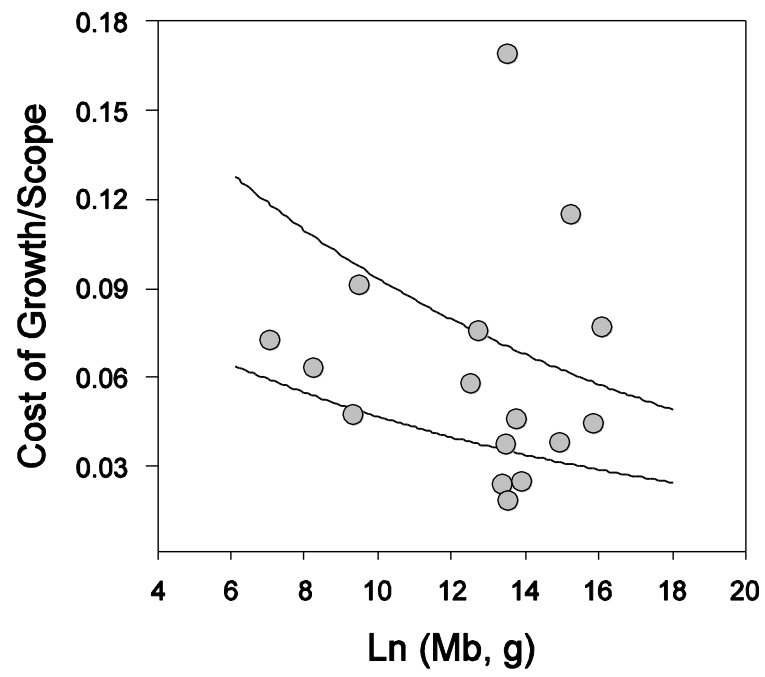

B

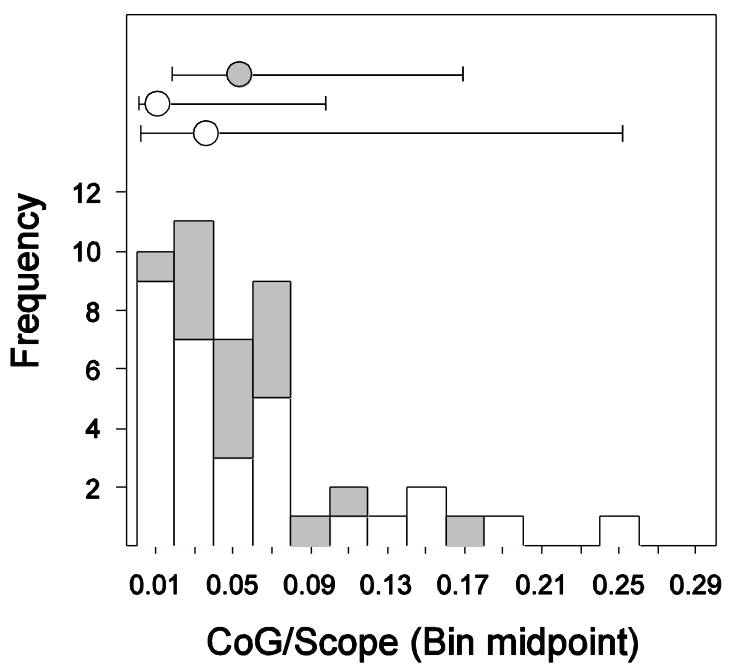

Figure 3. A. Thermodynamic cost of growth (fraction of the absolute metabolic scope) as a function of body mass $(\mathrm{Mb}, \mathrm{g})$ in dinosaurs. The lines are model estimates for a herbivore with $\mathrm{Tb} 25^{\circ} \mathrm{C}$ (upper) and an active predator with $\mathrm{Tb} 35^{\circ} \mathrm{C}$ (lower). Individual data points are for those dinosaurs for which we have estimates of annual growth rate. B. Frequency histograms of cost of growth as a fraction of metabolic scope for reptiles ( $\mathrm{Tb} 25^{\circ} \mathrm{C}$, white bars) and dinosaurs $\left(\mathrm{Tb} 35^{\circ} \mathrm{C}\right.$, grey bars). The skewness is caused by back-transformation from scaling relationships based on logarithmically transformed variables. Also shown are the geometric mean and range for reptilian data with $\mathrm{Tb}$ of $25^{\circ} \mathrm{C}$ (lower white symbol) and $35^{\circ} \mathrm{C}$ (upper white symbol) and for dinosaurs with $\mathrm{Tb} 35^{\circ} \mathrm{C}$ (grey symbol).

A key constraint is then whether the metabolic scope is sufficient to support the thermodynamic costs of growth. The observed scaling relationship for dinosaur growth (figure 2A) can be used to estimate the cost of growth as a fraction of absolute metabolic scope (figure 3A). The difficulty here is that we lack knowledge of the other non-basal metabolic costs to judge precisely when the costs of growth become too great to be supported 
by a purely reptilian metabolic scope. A calibration can be provided by calculating the cost of growth as a fraction of metabolic scope for living reptiles. Daily growth rate data were taken from Case (1978a) and metabolic scope estimated for a lizard of $\mathrm{Tb} 25^{\circ} \mathrm{C}$ and $35^{\circ} \mathrm{C}$. The estimated fraction of the scope needed to fuel the cost of growth in living reptiles overlaps extensively with the dinosaur data (figure 3B). This would suggest that a reptilian physiology would provide sufficient metabolic scope to fuel the thermodynamic cost of observed growth in dinosaurs. Modelled relationships for representative carnivorous and herbivorous dinosaurs (figure 3A) suggest that it is only for smaller ectothermic herbivorous dinosaurs with a body temperature $<\sim 20^{\circ} \mathrm{C}$ that the thermodynamic costs of growth approach levels that would appear to be unsustainable. The converse of this is that the warm body of larger dinosaurs was thus important in allowing the generation of sufficient metabolic scope to fuel the thermodynamic (overhead) costs of their faster growth rates.

The very fast growth rates suggested for Apatosaurus and Maiasaura (Erickson et al. 2001), however, incur thermodynamic costs that would utilise almost all of the non-locomotor fraction of the metabolic scope (see ESM); this would suggest that these growth rates are energetically unfeasible for a dinosaur with a purely reptilian physiology.

\section{Balancing the budget}

The only true way to balance an energy budget is to have independent estimates of the two sides of the energy budget equation: does the measured consumption match the measured rates of growth and energy dissipation?

A

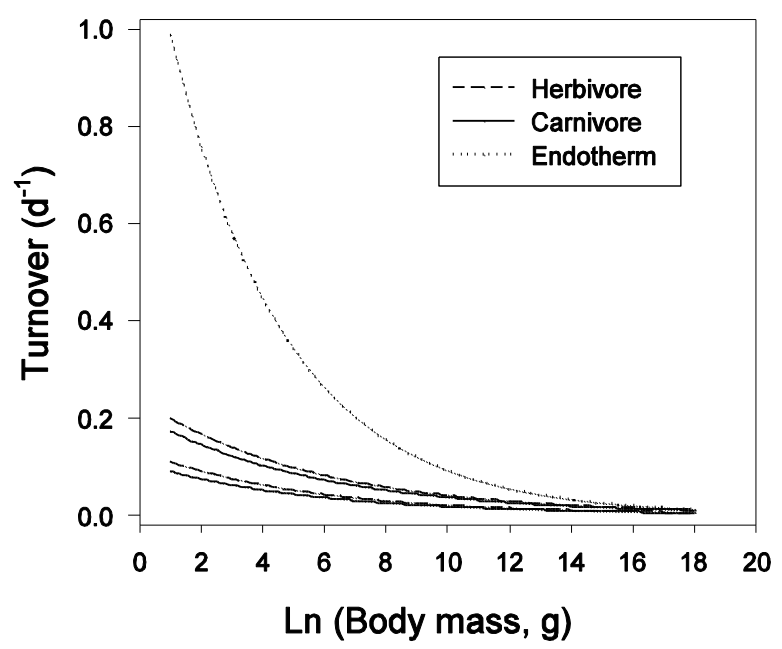

B

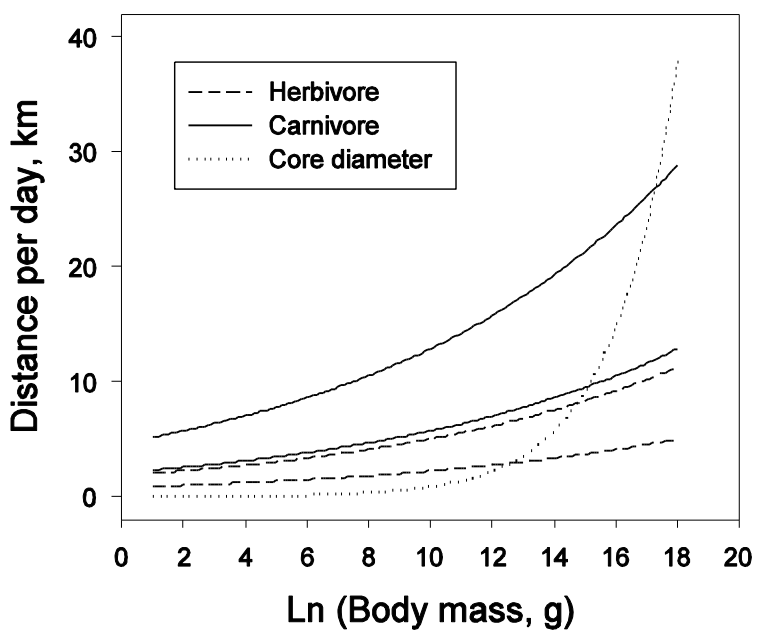

Figure 4. A. Turnover number (fraction of body energy consumed per day) for dinosaurs modelled as ectotherms (solid and dashed lines) and endotherms $\left(\mathrm{Tb} 37.5^{\circ} \mathrm{C}\right.$, dotted line). The ectotherm lines are modelled estimates for a herbivore (dashed line) and an active predator (solid line); in each case data are shown for $\mathrm{Tb} 25^{\circ} \mathrm{C}$ (lower) and $35^{\circ} \mathrm{C}$ (upper). B. Relationship between daily travel distance $(\mathrm{km})$ and body mass ( $\mathrm{g}$ ) in dinosaurs; presentation as for A. Also shown (dotted line) is the diameter of core home range extrapolated from data for living lizards (Christian and Waldschmidt 1984), assuming core range is $25 \%$ estimated home range (Stone and Baird 2002).

Clearly this is impossible for extinct taxa such as dinosaurs. What we can do, however, is estimate total food demand and see how this compares with extant terrestrial vertebrates. The 
overall energy flux through an organism is best expressed as a turnover number, this being the fraction of body energy (or carbon) that is utilised per unit time (here per day).

The turnover numbers for dinosaurs modelled as ectotherms (figure 4A) are greater than a previous estimate of the daily energy requirement estimated for Maiasaura (Dunham et al. 1989) and also slightly greater than those typically observed in living reptiles (Farlow 1976). This is to be expected, given the generally higher Tb values and faster growth rates of dinosaurs compared with extant reptiles. For dinosaurs with a physiology that approached even partially that of modern endotherms, metabolism and food consumption would have been significantly higher than estimated here for a purely reptilian physiology, but nowhere near that of mammals. For dinosaurs modelled as endotherms the turnover numbers are slightly lower than in mammals. This difference is also to be expected as the rate of energy throughput in endotherms is dominated by metabolism, which here is modelled from mammal data but the energy required for growth is less in dinosaurs than in living mammals (figure $2 \mathrm{~b}$ ). These turnover numbers indicate that parameterisation as either an ectothermic or endothermic metabolism, coupled with observed dinosaur growth rates, leads to reasonable estimates of daily energy intake.

\section{Discussion}

A thermodynamically rigorous power budget can be constructed for dinosaurs, and balanced within general constraints applying to all vertebrates. The upper boundary for feasible dinosaur physiologies is set by full endothermy, though the maximum size for a fully endothermic dinosaur is likely to have been well below the maximum size attained by some dinosaur lineages. The fossil record of herbivorous mammals shows a steady increase in maximum body size through the Cenozoic, to a maximum of $\sim 17$ tonnes in the early Oligocene Indricotherium and again in several Miocene species of Deinotherium (Smith et al. 2010). Mammalian carnivores show a similar trajectory but the maximum size attained is much less ( $\sim 1$ tonne). Whilst the configuration of the digestive system may constrain maximum size in mammalian herbivores (Clauss et al. 2003), it seems likely that the ultimate constraint on body size is set by the need to lose the heat generated by their metabolism (Smith et al. 2010; Speakman and Król 2010). The lower maximum size of carnivores may be set by physiological and ecological constraints on the ability to capture resources (Carbone et al. 2007). Considerations of heat flow thus suggest that the very largest dinosaurs were unlikely to have been endotherms comparable to living mammals and birds.

\section{Large dinosaurs as warm reptiles}

Much of the discussion surrounding the suggested elevated metabolic rate in the larger nonavian dinosaurs has centred on the need to power growth (Reid 1997a; Sander and Clauss 2008; Sander et al. 2011). To resolve this issue it is important to distinguish clearly the key pathways of energy flow in growth. The energy required for new tissue is typically provided directly from ingested food, and can be estimated from the known energy density of vertebrate tissue. Within limits, an enhanced growth rate simply requires a greater food intake. The critical constraints here are twofold: whether the organism can acquire the necessary food, and whether that food can be processed sufficiently rapidly by the gut. The processing of food in the gut is often the rate-limiting step in growth (Jeschke et al. 2002), but both of these processes will be aided by the warmer body resulting from thermal inertia in 
larger individuals, since both muscular power output and speed of digestion are enhanced by a higher body temperature (Clarke and Pörtner 2010).

Dunham et al. (1989) tackled the question of digestive constraints by using scaling relationships for gut length taken from extant ungulates and concluded that such constraints would indeed have limited the maximum growth rate that could be achieved by a herbivorous dinosaur such as Maiasaura, assuming a reptilian metabolism. Lehmann (2007) used scaling relationships for gut size and throughput to assess whether Chasmosaurus could process sufficient food to fuel an estimated endothermic metabolism, and concluded that it could not. This matches the conclusion of Weaver (1983) who argued that sauropods could not have been endotherms because they would not have been able to capture and digest sufficient food to sustain a mammal-like metabolism. Using a slightly different scaling approach, Franz et al. (2009) concluded that sauropods would have had sufficient gut volume to avoid digestive constraints on size. These various studies ask slightly different questions but arrive at very different conclusions; at present there is no consensus concerning possible digestive constraints on dinosaur energetics.

Additional to the energy invested in new tissue is the thermodynamic cost of growth $(\mathrm{CoG})$, which must be met from the metabolic scope (and ultimately also by food intake). The energetics model suggests that a warm reptilian physiology would have provided sufficient scope; the warm body of larger dinosaurs was thus critical in generating sufficient metabolic scope to meet the energetic requirements of growth. There would appear to be no need to hypothesise either an intermediate metabolism or endothermy simply to power the growth rates of currently known for dinosaurs.

Previous thermal modelling (Spotila 1980; O’Connor and Dodson 1999; Seebacher 2003), isotopic analysis (Eagle et al. 2011) and the model developed here all suggest that the resting metabolic rate of large dinosaurs is likely to have been that of a warm reptile. The temperature sensitivity of reptilian BMR means that an increase in mean daily body temperature from $25^{\circ} \mathrm{C}$ to $40^{\circ} \mathrm{C}$ would increase BMR by a factor of $\sim 3.4$. This is, however, still a reptilian metabolism, well below that of a living bird or mammal of the same body mass and temperatures (figure 1A). The difference between the endotherm and ectotherm BMR for the same body mass and temperature is substantial, emphasising the significant metabolic cost to being an endotherm. There is no need a priori to hypothesise a downregulation of metabolic rate with age (Pierson 2009) or a reduction of metabolic rate to avoid overheating at large sizes (Perry et al. 2009).

Whilst the metabolic rate of a warm reptile is less than that of an endotherm (figure 1a), it nevertheless represents a significant increase over many extant reptiles. It is possible that the respiration rate required to support such a metabolic rate was only possible because of the existence of avian-like air sacs, with the attendant possibility of a through-flow continuous ventilation system (Wedel 2003a, b; O'Connor and Claessens 2005; Sereno et al. 2008; Tickle et al. 2012). Among living amniotes, pneumatic postcranial bones are present only in birds, and they are the osteological correlates of the diverticular lungs and pulmonary air sacs (Wedel 2006). They extend as far back as the sauropodomorph Thecodontosaurus and the theropod Coelophysis (Wedel 2006, 2009) and thus appear to have evolved early in the Saurischia. This poses an intriguing question as to the metabolic level achievable by ornithischian dinosaurs, which appear to lack a through-flow ventilator system. 
We can use the estimated metabolic scope together with a general relationship for the cost of locomotion in terrestrial vertebrates (Pontzer 2007) to assess the capacity of dinosaurs to move across the landscape in search of food and mates. For dinosaurs modelled as simple ectotherms, conversion of the metabolic scope available for locomotor activity to a daily potential travel distance suggests that a potential core home range size greater than that predicted from studies of living reptiles (figure 4B). The caveat here is that the lizard home range data are for small taxa only $(<200 \mathrm{~g})$, and the scaling relationship for home range has very low precision, so extrapolating to body mass values typical of dinosaurs is highly speculative. But current data do suggest that a reptilian physiology would have allowed dinosaurs to cover a reasonable home range. For an endothermic dinosaur the metabolic scope would have allowed for a much greater home range.

The predicted daily travel distance increases only slowly with body mass (figure $4 \mathrm{~b}$ ). At body mass values typical of sauropods, daily travel distances estimated from the energetic model $\left(\sim 5 \mathrm{~km} \mathrm{~d}^{-1}\right)$ are less than those estimated from trackways (20-40 $\mathrm{km} \mathrm{d}^{-1}$ : Fastovsky and Weishampel 2009). The different metabolic scope assumed for carnivores results in larger estimates of daily travel distance $\left(\sim 20 \mathrm{~km} \mathrm{~d}^{-1}\right)$, and this emphasises the sensitivity of the estimated daily travel distance to underlying assumptions in the model. Nevertheless it is encouraging that the two estimates, from energetic modelling and trackways, are as close as they are.

\section{Reproductive output in dinosaurs}

The energetic model was constructed for a subadult dinosaur at the point in its life cycle when growth rate was maximal, and hence the respiratory overheads resulting from the thermodynamic cost of growth at its peak. Building the model for a subadult dinosaur also avoided the need to estimate reproductive costs. However a recent study of the reproductive output of lizards (Meiri et al. 2012) allows for a preliminary estimate of the reproductive output of dinosaurs. In extant lizards, annual reproductive output scales with body mass, with oviparous taxa having on average a slightly higher output than viviparous taxa (Meiri et al. 2012). It is not straightforward to estimate the annual reproductive output of dinosaurs. Varricchio et al. (2008) provide estimates of the volume of the total egg clutch for nine dinosaur taxa; if it is assumed that dinosaurs produced a single clutch of eggs per year, then their annual reproductive output is reasonably well described by an extrapolation of the scaling relationship for extant oviparous reptiles (figure 5A).

The initial model of dinosaur energetics can then be extended to include this estimate of annual reproductive output. If it is assumed that the fraction of absolute scope that is utilised by growth rate at its maximum represents a limit to the combined thermodynamic costs (overheads) of growth and reproductive synthesis, then this builds into the model an enforced trade-off between investment in growth and in reproduction. This is not unreasonable given that sexual maturation appears to occur in dinosaurs well before adult size is reached (Erickson et al. 2007). Applying this trade-off to growth in Tyrannosaurus (data from Erickson et al. 2004) suggests that sexual maturation started at an age of $\sim 16$ years and that maximum reproductive output was achieved by age $\sim 20-22$ years (figure $5 b$ ). These estimates are necessarily very approximate given the assumptions involved, but they match nicely the estimates of $18 \pm 2$ years from Schweitzer at al. (2005) and 18 years from Lee and Werning (2008) for the onset of sexual maturity in Tyrannosaurus. Using alternative growth 
models for Tyrannosaurus changes the estimates of growth rate and reproductive output, but not the timing of sexual maturity.

A

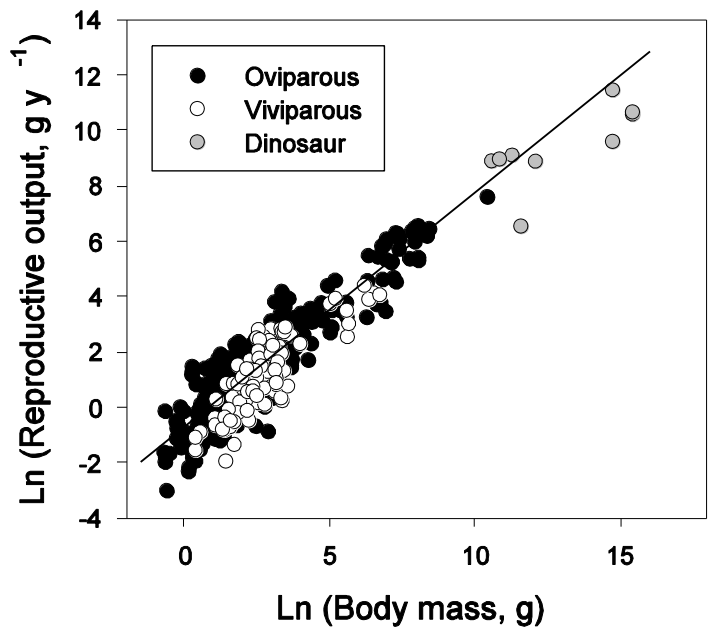

B

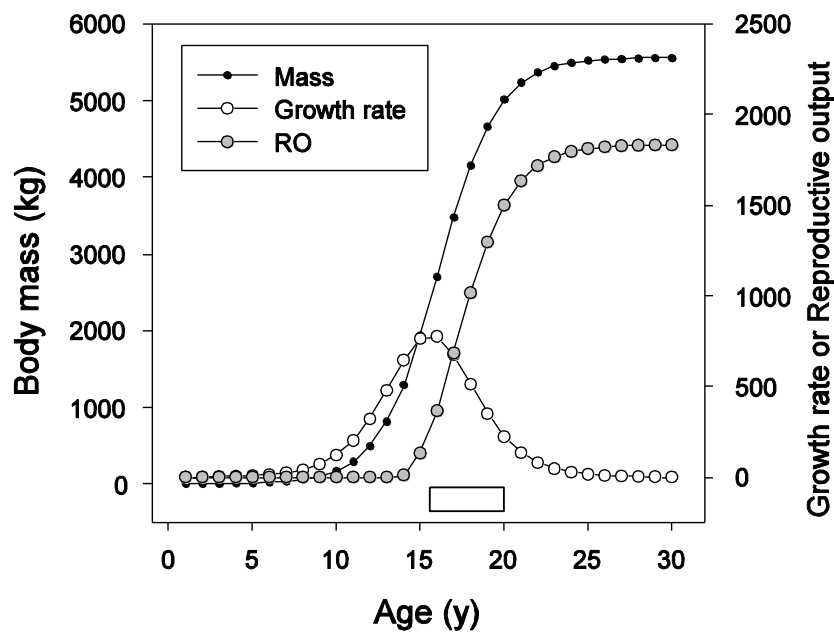

Figure 5. Reproductive output in dinosaurs. A. Scaling relationship between annual reproductive output in oviparous (black symbols and regression line) and viviparous lizards (white symbols) (data from Meiri et al. 2012). Also shown are estimates for dinosaurs from Varricchio et al. (2008) (grey symbols). B. Growth model for Tyrannosaurus rex (Erickson et al. 2004): body mass (black symbols) and annual growth rate $\left(\mathrm{kg} \mathrm{y}^{-1}\right.$, white symbols) as a function of age. Also shown is an estimate of annual reproductive output ( $\mathrm{g} \mathrm{y}^{-1}$, grey symbols). The bar shows the range of estimates of the timing of the onset of sexual maturity from Schweitzer et al. (2005) and Lee and Werning (2008).

\section{The breadth of dinosaur energetics and lifestyles}

The quantitative energetics model developed here suggests that simple ectothermy was a feasible physiology for dinosaurs, in that a warm reptilian physiology could have sustained many dinosaur lifestyles, as far as we can document them. There is thus no need a priori to invoke either endothermy or an intermediate metabolism, although neither does the model rule out these possibilities. However we know that at least one dinosaur lineage, that leading to birds, evolved true endothermy. Clearly there was no single dinosaur physiology: it would seem likely that dinosaurs exhibited a range of physiologies to match the breadth of their ecologies.

Small active forms would have required behavioural thermoregulation to maintain a high body temperature during the day, and presumably had ecologies similar to those of modern lizards. Slow-moving herbivorous dinosaurs may well have been purely ectothermic, though moderate to large sized individuals would have been able to maintain relatively warm bodies for much of the year over a wide range of palaeolatitudes (Seebacher 2003). Larger forms would have been able to maintain a warm or very warm body, and could therefore have sustained a fairly active lifestyle.

Perhaps the most interesting physiology was that of sauropods. Modelling work (Spotila et al. 1973; Spotila 1980; O'Connor and Dodson 1999) indicates clearly that they would have had a warm body through thermal inertia, and this has been confirmed by recent isotopic analysis (Eagle et al. 2011). The sauropod lifestyle could thus be viewed as quite distinct from both true endothermy and the ectotherm physiology of living reptiles because their enormous size results in a high and stable body temperature. A combination of large size 
with an ectothermic (reptilian) physiology is thus an alternative route to achieving a warm body (Hotton 1980) with all the attendant benefits for metabolic power generation, muscle power output, rates of digestion and other physiological processes, but without the need for costly endothermy (Clarke and Pörtner 2010). The high body temperature of sauropods would have resulted in an increased resting metabolic rate through the universally observed relationship between body temperature and basal metabolism, but it would still have been well below that of a modern endotherm extrapolated to sauropod body masses. Although this physiology simply represents extrapolation of a modern reptilian metabolism to very large size and high body temperature, there is a strong case for regarding this as truly unique, but now sadly lost for there are no modern analogues.

At least one dinosaur lineage, of course, did evolve endothermy, and it may be that metabolic rates started to approach modern endotherm levels quite early in this lineage (Werning et al. 2012). The trend towards endothermy may have started amongst small, active predatory forms (Seebacher 2003). These would have had the most difficulty in maintaining a high body temperature (Geiser et al. 2002), and hence some form of insulation would have been needed early on (Clarke and Pörtner 2010), but were probably more able to run swiftly than the larger forms (Thulborn 1982; Hutchinson 2004).

Asking whether dinosaurs were ectothermic or endothermic is thus posing a false dichotomy (Reid 1997a). Dinosaurs came in a huge range of sizes and shapes, they lived in a wide variety of habitats and exhibited diverse ecologies and life-styles. Schmitz and Motani (2011) have suggested that the eyes of Mesozoic archosaurs were adapted to all major types of diel activity: flyers were predominantly diurnal, terrestrial predators at least partially nocturnal, and large herbivores cathemeral. This analysis points clearly to a wide range of archosaur ecologies. Concomitant with this ecological diversity must have been a range of levels of metabolic intensity, from classic poikilothermic ectotherms, through high body temperature inertial homeotherms, to incipient or full endotherms. It is sad that some of these have left no living descendents for us to study, nor are there any modern analogues for such fascinating physiologies as the sauropods. The more we learn of dinosaur ecology and physiology, the more intriguing they become.

\section{Fossil evidence of dinosaur physiology}

The fossil evidence pertaining to dinosaur physiology has been reviewed thoroughly and often (Bakker 1980; Ruben et al. 1997; Fastovsky and Weishampel 2009; Brusatte 2012), with no consensus emerging. The problem we face is that physiology leaves little trace in the fossil record, and hence we can infer metabolic status only from proxies or indirect evidence. Some recent studies have, however started to provide a more consistent picture.

Early isotopic studies suggesting high body temperatures in a range of dinosaurs (Barrick et al. 1996, 1997) suffered from the technical difficulty of calibration: without knowledge of the isotopic composition of the fluids from which a biomineral was precipitated it is impossible to determine temperature absolutely. To circumvent this problem Amiot et al. (2006) had to assume an isotopic composition for body fluids, whereas Amiot et al. (2011) used the composition of modern meteoric water. Although these assumptions mean that the estimated body temperatures must be treated with caution, these studies were important in establishing systematic differences between different dinosaur lineages and the extent of variation in body temperature within a single individual. 
Recently, however, Eagle et al. (2011) have used clumped isotope thermometry to establish absolute body temperatures of $36-38^{\circ} \mathrm{C}$ in Jurassic sauropods. This technique does not depend on knowing (or assuming) the isotopic composition of the body fluids from which the biomineral grew. These data represent the most reliable estimates of $\mathrm{Tb}$ we have for any dinosaur, and they confirm the results of thermal modelling.

Isotopic data thus point clearly to stable high body temperatures in larger dinosaurs, but a warm body does not equate necessarily with endothermy. Anatomical evidence for a metabolic rate elevated above that of a typical reptile comes from the presence of respiratory turbinates, bone vascularisation, and the presence of fur or feathers for insulation. At present these various lines of evidence do not provide a consistent picture. Respiratory turbinates appeared fairly early in the therapsid lineage (Laass et al. 2011) but amongst dinosaurs the first clear indication is not until the Cretaceous ornithurine (that is, crown group) birds. Furthermore the scaling of nasal passage cross-sectional area suggests that there was no room to house respiratory turbinates in dinosaurs (Hillenius and Ruben 2004; but see Witmer 2001).

Recently Seymour et al. (2012) have examined the vascularisation of long bones in dinosaurs, comparing this with mammals and extant reptiles. The scaling of foramen area with bone length for femurs is distinctly different in mammals and non-varanid reptiles, being greater in mammals. An index of blood flow through the foramina correlates well with maximum metabolic rates during exercise in mammals and reptiles. Intriguingly, the blood-flow index calculated for a range of dinosaurs matches neither the mammal nor the reptile data, being higher than either. This might suggest that a high metabolic rate was widespread across all dinosaurs, but it may also mean that the relationship between blood flow and bone vascularisation was fundamentally different from either mammals or extant reptiles and hence is difficult to interpret.

It has long been assumed that lines of arrested growth (LAGs) were exclusively a feature of ectotherms, and that endotherm bone was characterised by continuously growing, wellvascularised fibrolamellar tissue without LAGs. Köhler et al. (2012) have recently demonstrated LAGs in 40 species of ruminant, from a wide range of habitats and climate regions, suggesting strongly that they are universal in this group. They have also been found in Pleistocene large mammals (Sander and Andrassy 2006). These studies indicate that in endotherms maximum rates of bone accrual are associated with periods of favourable growth and thus higher metabolic rates. The presence of LAGS in both mammals and many dinosaurs does not demonstrate that dinosaurs were endotherms, or that they were not; it simply indicates that ruminant mammals and dinosaurs both exhibit a seasonal physiology.

\section{Other extinct reptilian taxa}

Although they are not dinosaurs, the metabolic status of pterosaurs has also attracted some debate, as powered flight is energetically expensive. Whilst the mode of flight in pterosaurs has been debated (Witton and Habib 2010), avian-like air-sacs have recently been described in the earliest pterosaurs (Butler et al. 2009) and it has long been recognised that at least some pterosaurs possessed integumentary structures resembling fur (Padian and Rayner 1993; Lü 2002). At present the evidence is equivocal, but it remains an intriguing possibility that pterosaurs represent a third evolution of endothermy, but in a clade that has become extinct. Isotopic evidence also suggests that some marine reptiles may have maintained a warm body, presumably through mechanisms for retaining metabolic heat analogous to those used by 
several groups of marine fishes today (Bernard et al. 2010). A broad view of vertebrate energetics thus emphasises the powerful ecological benefits to be obtained from a warmer body, but also that endothermy is only one way of achieving those benefits (and a very expensive one at that).

\section{Summary and future perspectives}

The model used here to explore feasible dinosaur physiologies does not demonstrate that all (or even some) dinosaurs were reptilian in their physiology. What it does show is that most growth rates estimated for dinosaurs appear to be compatible with a reptilian physiology, especially where body temperatures are high, whilst also allowing sufficient energy for utilising a reasonable home range. The results presented here thus define a lower bound to thermodynamically feasible dinosaur physiologies. As such they place the burden of proof on the demonstration of full endothermy or some form of elevated or intermediate metabolism in dinosaurs.

An important caveat is that the model deals explicitly with energy flow averaged over a day, whereas animals in the real world have to contend with minute to minute variations in metabolic demand. A recent analysis of the energetics of movement in Tyrannosaurus, for example, suggested that instantaneous power required for locomotion could be met only from the metabolic scope characteristic of an endotherm (Pontzer et al. 2009).

Whilst there is neither consistency in the evidence nor consensus in its interpretation, it is possible to draw a broad picture of dinosaur energetics. The only dinosaur lineage within which endothermy is known to have evolved, that leading to birds, evolved air sacs and insulation early. This lineage also remained generally small at least until the Cenozoic, in agreement with arguments from thermal ecology (Seebacher 2003). Many other lineages evolved large size, where thermal inertia would have resulted in a stable and high body temperature. These lineages would have benefitted from the higher metabolic and muscular power output that comes with a warm body, but without the costs and associated problems of heat loss that come with endothermy. Firm evidence for the existence of insulation will always be difficult to obtain away from the exquisitely preserved fossils in Lagerstätten. It seems likely that the best prospect of immediate progress with understanding the evolution and phylogenetic prevalence of endothermy will come from extending studies of bone osteology and the new generation of multiple isotope proxies to a wider range of dinosaur lineages.

In particular it would be profitable to broaden attention from the relatively well-studied sauropods and larger theropods, and examine smaller non-theropod taxa, together with representatives of lineages that would appear from their anatomy to have remained resolutely ectothermic (such as ankylosaurs), and those ornithischian lineages with indications of an active lifestyle, such as hadrosaurs. We will then be in a stronger position to undertake more balanced comparative studies, and thereby sharpen our understanding of dinosaur physiology.

\section{Acknowledgements}

I thank Mike Angilletta and two anonymous referees for perceptive reviews that helped improve the paper significantly. Drew Lee, Tom Hübner \& Greg Erickson were very helpful 
in answering queries and providing dinosaur growth data. I also thank all those physiologists and palaeobiologists with whom I have discussed dinosaur physiology over the years. They will not all agree with the views expressed here, but the discussions have always been rewarding and fun. This work was undertaken supported through an emeritus position at the British Antarctic Survey, Cambridge, and an honorary position at the University of East Anglia.

\section{Literature cited}

Amiot, R., C. Lecuyer, E. Buffetaut, G. Escarguel, F. Fluteau, and F. Martineau. 2006. Oxygen isotopes from biogenic apatites suggest widespread endothermy in Cretaceous dinosaurs. Earth and Planetary Science Letters 246:41-54.

Amiot, R., X. Wang, Z. Zhou, X. Wang, E. Buffetaut, C. Lécuyer, Z. Ding et al. 2011. Oxygen isotopes of East Asian dinosaurs reveal exceptionally cold Early Cretaceous climates. Proceedings of the National Academy of Sciences of the United States of America 108:5179-5183.

Angilletta, M. J., B. S. Cooper, M. S. Schuler, and J. G. Boyles. 2010. The evolution of thermal physiology in endotherms. Frontiers in Bioscience E2:861-881.

Bakker, R. T. 1980. Dinosaur heresy - dinosaur renaissance: why we need endothermic archosaurs for a comprehensive theory of bioenergetic evolution, Pages 351-462 in R. D. K. Thomas, and E. C. Olson, eds. A cold look at the warm-blooded dinosaurs. AAAS Selected Symposia Series 28. Washington, D.C., Westview Press, for the American Association for the Advancement of Science.

Barrick, R. E., W. J. Showers, and A. G. Fischer. 1996. Comparison of the thermoregulation of four ornithischian dinosaurs and a varanid lizard from the Cretaceous two medicine formation: evidence from oxygen isotopes. Palaios 11:295-305.

Barrick, R. E., M. K. Stoskopf, and W. J. Showers. 1997. Oxygen isotopes in dinosaur bone, Pages 474-490 in J. O. Farlow, and M. K. Brett-Surman, eds. The complete dinosaur. Bloomington, Indiana University Press.

Beaupre, S. J., A. E. Dunham, and K. L. Overall. 1993. The effects of consumption rate and temperature on apparent digestibility coefficient, urate production, metabolizable energy coefficient and gut passage time in canyon lizards (Sceloporus merriami) from two populations. Functional Ecology 7:273-280.

Bell, P. R., and E. Snively. 2008. Polar dinosaurs on parade: a review of dinosaur migration. Alcheringa 32:271 284.

Bernard, A., C. Lécuyer, P. Vincent, R. Amiot, N. Bardet, E. Buffetaut, G. Cuny et al. 2010. Regulation of body temperature by some Mesozoic marine reptiles. Science 328:1379-1382.

Blaxter, K. L. 1989, Energy metabolism in animals and man. Cambridge, Cambridge University Press.

Brown, J. H., J. F. Gillooly, A. P. Allen, V. M. Savage, and G. B. West. 2004. Toward a metabolic theory of ecology. Ecology 85:1771-1789.

Brown, T. K., and K. A. Nagy. 2007. Lizard energetics and the sit-and-wait vs. wide-foraging paradigm, Pages 120-140 in S. M. Reilly, L. D. McBrayer, and D. B. Miles, eds. Lizard ecology: the evolutionary consequences of foraging mode. Cambridge, Cambridge University Press.

Brusatte, S. L. 2012, Dinosaur paleobiology: Topics in paleobiology. Chichester, Wiley-Blackwell.

Butler, R. J., P. M. Barrett, and D. J. Gower. 2009. Postcranial skeletal pneumaticity and air-sacs in the earliest pterosaurs. Biology Letters 5:557-560.

Carbone, C., A. Teacher, and J. M. Rowcliffe. 2007. The costs of carnivory. PLoS Biology 5:e22.

Case, T. J. 1978. On the evolution and adaptive significance of postnatal growth rates in the terrestrial vertebrates. Quarterly Review of Biology 53:243-282.

- 1978. Speculations on the growth rate and reproduction of some dinosaurs. Paleobiology 4:320-328.

Chinsamy, A., D. B. Thomas, A. R. Tumarkin-Deratzian, and A. R. Fiorillo. 2011. Hadrosaurs were perennial polar residents. Anatomical Record 295:610-614.

Christian, K. A., R. V. Baudinette, and Y. Pamula. 1997. Energetic costs of activity by lizards in the field. Functional Ecology 11:392-397.

Christian, K. A., and S. Waldschmidt. 1984. The relationship between lizard home range and body size: a reanalysis of the data. Herpetologica 40:68-75.

Clarke, A. 1987. Temperature, latitude and reproductive effort. Marine Ecology Progress Series 38:89-99.

Clarke, A., and H. O. Pörtner. 2010. Temperature, metabolic power and the evolution of endothermy. Biological Reviews 85:703-727.

Clarke, A., and P. Rothery. 2008. Scaling of body temperature in birds and mammals. Functional Ecology 
22:58-67.

Clarke, A., P. Rothery, and N. J. B. Isaac. 2010. Scaling of basal metabolic rate with body mass and temperature in mammals. Journal of Animal Ecology 79:610-619.

Clauss, M., R. Frey, B. Kiefer, M. Lechner-Doll, W. Loehlin, C. Polster, G. E. Rössner et al. 2003. The maximum attainable body size of herbivorous mammals: morphological constraints on foregut, and adaptations of hindgut fermenters. Oecologia 136:14-27.

Dunham, A. E., K. L. Overall, W. P. Porter, and C. A. Forster. 1989. Implications of ecological energetics and biophysical and developmental constraints for life-history variation in dinosaurs, Pages 1-19 in J. O. Farlow, ed. Paleobiology of the dinosaurs. Geological Society of America Special Paper 238. Boulder, Colorado, Geological Society of America.

Eagle, R. A., T. Tütken, T. S. Martin, A. K. Tripati, H. C. Fricke, M. Connely, R. L. Cifelli et al. 2011. Dinosaur body temperatures determined from isotopic $\left({ }^{13} \mathrm{C}-{ }^{18} \mathrm{O}\right)$ ordering in fossil biominerals. Science 333:443445.

Erickson, G. M., K. Curry Rogers, D. J. Varricchio, M. A. Norell, and X. Xu. 2007. Growth patterns in brooding dinosaurs reveals the timing of sexual maturity in non-avian dinosaurs and genesis of the avian condition. Biology Letters 3:558-561.

Erickson, G. M., P. J. Mackovicky, P. J. Currie, M. A. Norell, S. A. Yerby, and C. A. Brochu. 2004. Gigantism and comparative life-history parameters of tyrannosaurid dinosaurs. Nature 430:772-775.

Erickson, G. M., K. C. Rogers, and S. A. Yerby. 2001. Dinosaurian growth patterns and rapid avian growth rates. Nature 412:429-433.

Etheridge, K., and L. C. Wit. 1993. Factors affecting activity in Cnemidophorus, Pages 151-162 in J. W. Wright, and L. J. Vitt, eds. Biology of whiptail lizards (genus Cnemidophorus). Norman, Oklahoma, Oklahoma Museum of Natural History.

Farlow, J. O. 1976. A consideration of the trophic dynamics of a late Cretaceous large-dinosaur community (Oldman Formation). Ecology 57:841-857.

Fastovsky, D. E., and D. B. Weishampel. 2009, Dinosaurs: a concise natural history. Cambridge, Cambridge University Press.

Franz, R., J. Hummel, E. Kienzle, P. Kölle, H.-C. Gunga, and M. Clauss. 2009. Allometry of visceral organs in living amniotes and its implications for sauropod dinsoaurs. Proceedings of the Royal Society of London, Series B 276:1731-1736.

Geiser, F., N. Goodship, and C. R. Pavey. 2002. Was basking important in the evolution of mammalian endothermy? Naturwissenschaften 89:412-414.

Gillooly, J. F., A. P. Allen, and E. L. Charnov. 2006. Dinosaur fossils predict body temperatures. PLoS Biology 4:e248 (1467-1469).

Gillooly, J. F., J. H. Brown, G. B. West, V. M. Savage, and E. L. Charnov. 2001. Effects of size and temperature on metabolic rate. Science 293:2248-2251.

Hammond, K. A., and J. Diamond. 1997. Maximal sustained energy budgets in humans and animals. Nature 386:457-462.

Hillenius, W. J., and J. A. Ruben. 2004. The evolution of endothermy in terrestrial vertebrates: who? when? why? Physiological and Biochemical Zoology 77:1019-1024.

Hotton, N. 1980. An alternative to dinosaur endothermy, Pages 311-350 in R. D. K. Thomas, and E. C. Olson, eds. A cold look at the warm-blooded dinosaurs. AAAS Selected Symposia Series 28. Washington, D.C., Westview Press, for the American Association for the Advancement of Science.

Hou, C., W. Zuo, M. E. Moses, W. H. Woodruff, J. H. Brown, and G. B. West. 2008. Energy uptake and allocation during ontogeny. Science 322:736-739.

Hulbert, A. J., and P. L. Else. 2000. Mechanisms underlying the cost of living in animals. Annual Review of Physiology 62:207-235.

—. 2004. Basal metabolic rate: history, composition, regulation, and usefulness. Physiological and Biochemical Zoology 77:869-876.

Hutchinson, J. R. 2004. Biomechanical modeling and sensitivity analysis of bipedal running ability. II. Extinct taxa. Journal of Morphology 262:441-461.

Jeschke, J. M., M. Kopp, and R. Tollrian. 2002. Predator functional responses: discriminating between handling and digesting prey. Ecological Monographs 72:95-112.

Kearney, M. 2012. Metabolic theory, life history and the distribution of a terrestrial ectotherm. Functional Ecology 26:167-179.

Köhler, M., N. Marín-Moratalla, X. Jordana, and R. Aanes. 2012. Seasonal bone growth and physiology in endotherms shed light on dinosaur physiology. Nature Early on-line.

Kooijman, S. A. L. M. 1993, Dynamic energy budgets in biological systems : theory and applications in ecotoxicology. Cambridge, Cambridge University Library.

—. 2000, Dynamic energy and mass budgets in biological systems. Cambridge, Cambridge University Press. 
-. 2009, Dynamic energy budget theory for metabolic organisation. Cambridge, Cambridge University Press.

Laass, M., O. Hampe, M. Schudack, C. Hoff, N. Kardjilov, and A. Hilger. 2011. New insights into the respiration and metabolic physiology of Lystrosaurus. Acta Zoologica 92:363-371.

Lee, A. H., and S. Werning. 2008. Sexual maturity in growing dinosaurs does not fit reptilian growth models. Proceedings of the National Academy of Sciences of the United States of America 105:582-587.

Lehman, T. M. 2007. Growth and population age structure in the horned dinosaur Chasmosaurus, Pages 259317 in K. Carpenter, ed. Horns and beaks: ceratopsian and ornithopod dinosaurs. Life of the past. Bloomington and Indianapolis, Indiana University Press.

Lü, J.-C. 2002. Soft tissue in an early Cretaceous pterosaur from Liaoning Province, China. Memoir of the Fukui Prefectural Dinosaur Museum 1:19-28.

McNab, B. K. 2009. Resources and energetics determined dinosaur maximal size. Proceedings of the National Academy of Sciences of the United States of America 106:12184-12188.

Meiri, S., J. H. Brown, and R. M. Sibly. 2012. The ecology of lizard reproductive output. Global Ecology and Biogeography 21:592-602.

Milligan, L. P., and M. Summers. 1986. The biological basis of maintenance and its relevance to assessing responses to nutrients. Proceedings of the Nutrition Society 45:185-193.

Moses, M. E., C. Hou, W. H. Woodruff, G. B. West, J. C. Nekola, W. Zuo, and J. H. Brown. 2008. Revisiting a model of ontogenetic growth: estimating model parameters from theory and data. American Naturalist 171:632-645.

Nagy, K. A. 2005. Field metabolic rate and body size. Journal of Experimental Biology 208:1621-1625.

O'Connor, M. P., and P. Dodson. 1999. Biophysical constraints on the thermal ecology of dinosaurs. Paleobiology 25:341-368.

O'Connor, P. M., and L. P. A. M. Claessens. 2005. Basic avian pulmonary design and flow-through ventilation in non-avian theropod dinosaurs. Nature 436:253-256.

Ostrom, J. H. 1969. Osteology of Deinonychus antirrhopus, an unusual theropod from the Lower Cretaceaous of Montana. Bulletin of the Peabody Museum of Natural History, Yale University 30:1-165.

-. 1970. Terrestrial vertebrates as indicators of Mesozoic climates. Proceedings of the North American Paleontological Convention, Chicago 1969 A:347-376.

Padian, K., and J. M. V. Rayner. 1993. The wings of pterosaurs. American Journal of Science 293 A:91-166.

Parry, G. D. 1983. The influence of the cost of growth on ectotherm metabolism. Journal of Theoretical Biology 101:453-477.

Perry, S. F., A. Christian, T. Breuer, N. Pajor, and J. R. Codd. 2009. Implications of avian-style respiratory system for gigantism in sauropod dinosaurs. Journal of Experimental Zoology (Ecological Genetics and Physiology) 311A:600-610.

Peterson, C. C., K. A. Nagy, and J. Diamond. 1990. Sustained metabolic scope. Proceedings of the National Academy of Sciences of the United States of America 87:2324-2328.

Petrusewicz, K., and A. Macfadyen. 1970, Productivity of terrestrial animals: principles and methods: International Biological Programme Handbook, v. No 13. Oxford, Blackwell Scientific Publications.

Pierson, D. J. 2009. The physiology of dinosaurs: circulatory and respiratory function in the largest animals ever to walk the Earth. Respiratory Care 54:887-911.

Pontzer, H. 2007. Effective limb length and the scaling of locomotor cost in terrestrial animals. Journal of Experimental Biology 210:1752-1761.

Pontzer, H., V. Allen, and J. R. Hutchinson. 2009. Biomechanics of running indicates endothermy in bipedal dinosaurs. PLoS ONE 4:e7783.

Reid, R. E. H. 1997. Dinosaurian physiology: the case for 'intermediate' dinosaurs, Pages 449-473 in J. O. Farlow, and M. K. Brett-Surman, eds. The complete dinosaur. Bloomington, Indiana University Press.

-. 1997. How dinosaurs grew, Pages 403-413 in J. O. Farlow, and M. K. Brett-Surman, eds. The complete dinosaur. Bloomington, Indiana University Press.

Ruben, J., A. Leitch, W. Hillenius, N. Geist, and T. Jones. 1997. New insights into the metabolic physiology of dinosaurs, Pages 505-518 in J. O. Farlow, and M. K. Brett-Surman, eds. The complete dinosaur. Bloomington, Indiana University Press.

Sander, P. M., and P. Andrassy. 2006. Lines of arrested growth and long bone histology in Pleistocene large mammals from Germany: what do they tell us about dinosaur physiology? Palaeontographica A (Palaozoologie, Stratigraphie) 277:143-159.

Sander, P. M., A. Christian, M. Clauss, R. Fechner, C. T. Gee, E.-M. Griebeler, H.-C. Gunga et al. 2011. Biology of sauropod dinosaurs: the evolution of gigantism. Biological Reviews 86:117-155.

Sander, P. M., and M. Clauss. 2008. Sauropod gigantism. Science 322:200-201.

Schmitz, L., and R. Motane. 2011. Nocturnality in dinosaurs inferred from scleral ring and orbit morphology. Science 332:705-708.

Schweitzer, M. H., J. L. Wittmeyer, and J. R. Horner. 2005. Gender-specific reproductive tissue in ratites and 
Tyrannosaurus rex Science 308:1456-1460.

Seebacher, F. 2003. Dinosaur body temperatures: the occurrence of endothermy and ectothermy. Paleobiology 29:105-122.

Sereno, P. C., R. N. Martinez, J. A. Wilson, D. J. Varricchio, O. A. Alcober, and H. C. E. Larsson. 2008. Evidence for avian intrathoracic air sacs in a new predatory dinosaur from Argentina. PLoS ONE 3:e3303.

Seymour, R. S., S. L. Smith, C. R. White, D. M. Henderson, and D. Schwarz-Wings. 2012. Blood flow to long bones indicates activity metabolism in mammals, reptiles and dinosaurs. Proceedings of the Royal Society of London, Series B 279:451-456.

Smith, F. A., A. G. Boyer, J. H. Brown, D. P. Costa, T. Dayan, S. K. M. Ernest, A. R. Evans et al. 2010. The evolution of maximum body size of terrestrial mammals. Science 330:1216-1219.

Southwood, A., and A. Larisa. 2010. Physiological, behavioral, and ecological aspects of migration in reptiles. Journal of Comparative Physiology B 180:1-23.

Speakman, J. R., and E. Król. 2010. Maximal heat dissipation capacity and hyperthermia risk: neglected key factors in the ecology of endotherms. Journal of Animal Ecology 79:726-746.

Spotila, J. R. 1980. Constraints of body size and environment on the temperature regulation of dinosaurs, Pages 233-252 in R. D. K. Thomas, and E. C. Olson, eds. A cold look at the warm-blooded dinosaurs. AAAS Selected Symposia Series 28. Washington, D.C., Westview Press, for the American Association for the Advancement of Science.

Spotila, J. R., P. W. Lommen, G. S. Bakken, and D. M. Gates. 1973. A mathematical model for body temperatures of large reptiles: implications for dinosaur ecology. American Naturalist 107:391-404.

Stone, P. A., and T. A. Baird. 2002. Estimating lizard home range: the Rose model revisited. Journal of Herpetology 36:427-436.

Thulborn, R. A. 1982. Speeds and gaits of dinosaurs. Palaeogeography, Palaeoclimatology, Palaeoecology 38:227-256.

Tickle, P. G., M. A. Norell, and J. R. Codd. 2012. Ventilatory mechanics from maniraptoran theropods to extant birds. Journal of Evolutionary Biology 25:740-747.

Varricchio, D. J. 2011. A distinct dinosaur life history? Historical Biology 23:91-107.

Varricchio, D. J., J. R. Moore, G. M. Erickson, M. A. Norell, F. D. Jackson, and J. J. Borkowski. 2008. Avian paternal care had dinosaur origin. Science 322:1826-1828.

Weaver, J. C. 1983. The improbable endotherm: the energetics of the sauropod Brachiosaurus. Paleobiology 9:173-182.

Wedel, M. J. 2003. The evolution of vertebral pneumaticity in sauropod dinosaurs. Journal of Vertebrate Paleontology 23:344-357.

- 2003. Vertebral pneumaticity, air sacs, and the physiology of sauropod dinosaurs. Paleobiology 29:243-255.

- 2006. Origin of postcranial skeletal pneumasticity in dinosaurs. Integrative Zoology 1:80-85.

—. 2009. Evidence for bird-like air sacs in saurischian dinosaurs. Journal of Experimental Zoology (Ecological Genetics and Physiology) 311A:611-628.

Werning, S., R. B. Irmis, S. J. Nesbitt, N. D. Smith, A. H. Turner, and P. K. 2012. Early evolution of elevated growth and metabolic rates in archosaurs. Integrative and Comparative Biology 52 (Supplement 1):E189.

West, G. B., J. H. Brown, and B. J. Enquist. 1997. A general model for the origin of allometric scaling laws in biology. Science 276:122-126.

-. 2001. A general model for ontogenetic growth. Nature 413:628-631.

Wieser, W. 1994. Cost of growth in cells and organisms: general rules and comparative aspects. Biological Reviews 68:1-33.

Witmer, L. M. 2001. Nostril position in dinosaurs and other vertebrates and its significance for nasal function. Science 293:850-853.

Witton, M. P., and M. B. Habib. 2010. On the size and flight diversity of giant pterosaurs, the use of birds as pterosaur analogues and comments on pterosaur flightlessness. PLoS ONE 5:e13982. 


\section{Online Appendix A: Model Structure and Parameterisation}

\section{1: Choice of the energy budget model}

An organism is an open thermodynamic system, continually exchanging both energy and materials with its environment. The traditional model for vertebrate energetics has long been the balanced energy budget developed during the International Biological Program (IBP) (Petrusewicz and Macfadyen 1970). In recent years, however, two quite different new approaches have been developed, namely Dynamic Energy Budget (DEB) theory and the Metabolic Theory of Ecology (MTE).

The IBP model is rigorous, and is based on decades of detailed physiological research (principally on mammals, many of them domesticated). It is usually constructed as a difference equation modelled in discrete time (with the time step typically between 1 day and 1 year) to capture the balance between energy intake and energy utilisation plus dissipation. The MTE couples a power law with a Boltzmann temperature correction to capture the size-dependency of metabolism. The power law follows from considerations of energy minimisation in a near-fractal circulatory system, and the temperature correction is the standard approach to temperature correction in simple physical systems (West et al. 1997; Gillooly et al. 2001; Brown et al. 2004). The Dynamic Energy Budget (DEB) model models energy flow from zygote to adult, emphasising important differences between reserves, structure and reproductive tissues. It is rigorous, and has the capacity to be both general and specific (Kooijman 1993, 2000, 2009).

The choice between these models was determined by what was required for the question being tackled. In general terms, a model should be as simple as possible, whilst capturing all of the essential features of the system (in other words, applying Occam's razor, simple but not too simple: Sousa et al. 2010). A major disadvantage of the MTE for the study reported here is that it does not allow for statistical interactions between the mass and temperature relationships nor does it allow estimation of the energy utilised in important ecological processes such as growth, reproduction or locomotion, although a number of extensions to the MTE do so (West et al. 2001; Gillooly et al. 2006; Moses et al. 2008; Hou et al. 2008).

The DEB model is more complex than the IBP formulation; for example Sousa et al. (2008) list 3 state variables, 14 variables and 18 parameters. Furthermore none of these state variables can be measured directly (Souse et al. 2010), which necessitates the development of auxiliary theory to link empirical measurements to the model (Kooijman et al. 2008). DEB theory has been applied very successfully to a number of organisms, including extant lizards (Kearney 2006) but this model requires a significant number of parameters and variables for which data are simply not available for dinosaurs.

Given the physiological question being posed in this study and the nature of the data available, the choice of the IBP formulation was straightforward. The question posed is simple, and the model is appropriate: it uses only two state variables, and minimises the requirement to estimate parameters and variables for dinosaurs from extant vertebrates. It also avoids the need to estimate features of the habitat, such as temperature or food availability, which are required for a DEB model but which cannot meaningfully be estimated for dinosaurs.

A model based on DEB theory would be valuable next step, but for the initial study undertaken here, the simpler (but still thermodynamically rigorous) IBP formulation was chosen. 


\section{2: The balanced energy budget}

The balanced energy budget is based on the premise that when averaged over some defined time period, the energy an organism takes from its environment matches exactly the energy dissipated in respiration, lost in excretion or sequestered in new tissue. The time averaging is important to integrate short-term imbalances that result from the various energy flows involved occurring at different rates. Thus:

$$
\mathrm{C}=\Sigma \mathrm{R}+\Sigma \mathrm{P}+\Sigma \mathrm{E}+\mathrm{F}
$$

where $\mathrm{C}$ is consumption, $\Sigma \mathrm{R}$ the total respiratory losses, $\Sigma \mathrm{P}$ the sum of all production (somatic tissue and gonads), $\Sigma \mathrm{E}$ the total excretory losses and $\mathrm{F}$ the unabsorbed energy voided as faeces. This is the traditional IBP formulation of the balanced energy budget, modified to make explicit the heterogeneous nature of respiratory demand (Clarke 1987).

This model follows directly from the First Law of Thermodynamics: the animal takes in chemical energy which is either retained in new tissue, used to perform work, excreted or dissipated as heat. A thermodynamically rigorous budget should also include a term for the change in heat content of the organism $(\Delta \mathrm{Q})$ because the exchange of thermal energy with the environment influences the total heat content of the organism and hence its body temperature. However it is usually assumed that either heat content remains constant (endotherms), or that the time frame over which the budget is calculated is sufficiently long for heat gains during the day to balance heat losses during the night. In both cases $\Delta \mathrm{Q} \sim 0$, and changes in heat content are therefore ignored in the traditional IBP formulation of the balanced energy budget. (For energy budgets that incorporate heat flow see Blaxter 1989 for mammals and Dunham et al. 1989 for the hadrosaur Maiasaura). The contribution to internal heat content from the oxidation of foodstuffs during metabolism is captured by the $\Sigma$ R term.

Most difficulty with parameterisation surrounds the respiration term $(\Sigma \mathrm{R})$. Typically respiration dominates the energy budget, though its importance differs between endotherms, where it constitutes a very large proportion of total energy throughput, and ectotherms where it is typically a smaller proportion of total energy use. The problem is that $\Sigma \mathrm{R}$ represents the dissipation of energy through a variety of different processes which may compete for resources.

An important component of $\Sigma \mathrm{R}$ is basal (maintenance) metabolism, BMR, which is usually estimated by a measure of resting metabolic rate. BMR is essentially the cost of maintaining a body of a given size and temperature. The processes comprising BMR many and varied, but key components include protein turnover, the maintenance of the internal cellular ionic environment through the activity of membrane ion pumps, and proton leak in mitochondria (Milligan and Summers 1986; Blaxter 1989; Hulbert and Else 2000, 2004). The important point here is that energy dissipated in BMR cannot contribute to ecologically important processes such as growth, reproduction or locomotor activity. These are fuelled by the metabolic scope, which is the respiration additional to BMR.

The major contributions to the metabolic scope are the cost of activity, Ra, which encompasses all the locomotor and behavioural costs of existence, the thermodynamic costs of growth $(\mathrm{CoG})$, and $\mathrm{Rm}$ which captures the respiratory costs of all those non-basal metabolic processes involved in everyday existence. Whilst Ra and CoG can be estimated from empirical data, we do not have a clear understanding of precisely what processes contribute to $\mathrm{Rm}$; Rm can therefore currently only estimated by difference.

The heterogeneous nature of respiration is thus:

$$
\Sigma \mathrm{R}=\mathrm{BMR}+[\mathrm{Ra}+\mathrm{CoG}+\mathrm{Rm}]
$$


Here the processes fuelled from the metabolic scope are grouped within square brackets. We can then relate the various components of the full balanced energy budget to the different measures of energetics of interest to ecologists:

Basal (resting) metabolic rate $=$ BMR

Sustained (field) metabolic rate, $\mathrm{FMR}=\mathrm{BMR}+[\mathrm{Ra}+\mathrm{Rm}+\mathrm{CoG}]=\Sigma \mathrm{R}$

Energy absorbed $=\mathrm{FMR}+(\mathrm{Ps}+\mathrm{Pg})+\Sigma \mathrm{E}$

Total energy demand $=\mathrm{C}=\mathrm{FMR}+(\mathrm{Ps}+\mathrm{Pg})+\Sigma \mathrm{E}+\mathrm{F}$

$\mathrm{Ra}, \mathrm{CoG}$ and $\mathrm{Rm}$ together comprise the metabolic scope, which is the difference between FMR and BMR. Metabolic scope can be expressed either as the absolute scope, or the relative scope:

Absolute metabolic scope $=\mathrm{FMR}-M b \mathrm{R}$

Relative metabolic scope $=$ FMR $/$ BMR

Absolute scope has dimensions of power, whereas absolute scope is dimensionless. The metabolic scope here is the field or sustained metabolic scope; it is lower than the maximum (sometimes called absolute) metabolic scope, which is the difference between BMR and maximum aerobic activity. The latter can only be sustained for a short period of time before exhaustion sets in. In contrast the sustained aerobic scope integrates short periods of intense activity with rest and routine behaviour to capture the long-term day-to-day rate of aerobic power requirement.

It is important to note that whilst a measure of FMR captures most of the energy requirement of a free-living organisms (because $\Sigma \mathrm{R}$ is typically the major component of the energy budget), it does not capture the total energy demand. The composition of the balanced energy budget can be shown diagrammatically (Figure A1)

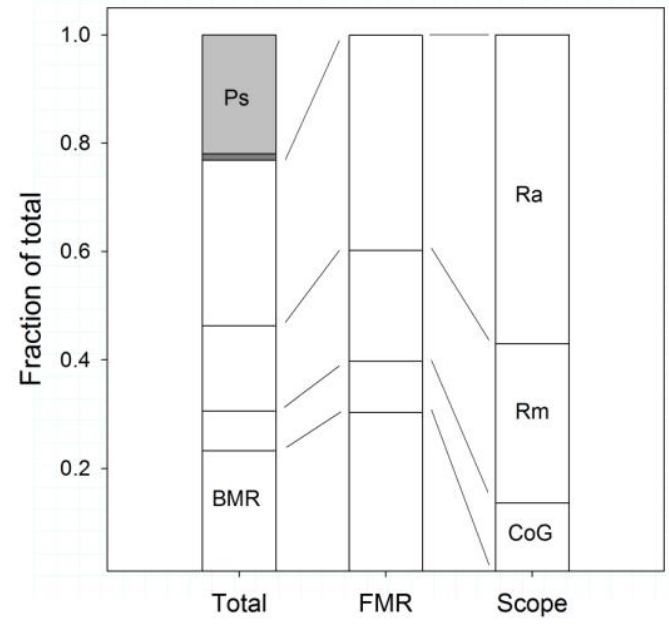

Figure A1. The balanced energy budget model. Energy sequestered in new tissue (Ps) is shown in grey, and energy assimilated but lost in excretory products is shown in dark grey. Energy assimilated but dissipated in respiration is shown in white. The relative proportions are based on a model of the energetics of an extant reptile of body mass $10 \mathrm{~kg}$. Abbreviations as in text.

The relative importance of the various components in the budget shown in Figure A1 is based on data for extant reptiles at the point in the life-cycle when growth is maximal. Key features of the structure of the balanced energy budget are that average daily energy expenditure (DEE or FMR) captures only part of the daily energy demand of the organism, and that the thermodynamic cost of growth (see below), non-basal metabolic processes and locomotor activity are all additional to BMR. 
The balance between the various components of the energy budget varies ontogenetically. In rapidly growing younger individuals, energy retained in new tissue constitutes a significant proportion of the energy budget; in older individuals where growth has all but ceased, FMR dissipates almost all of the absorbed energy.

\section{3: Estimating the components of the energy budget for dinosaurs}

The central assumption of this analysis is that extant taxa can inform us about extinct taxa. The history of palaebiology shows us clearly that inferring how dinosaurs lived from observations of living mammals and reptiles is fraught with problems. Some empirical data can be taken directly from dinosaurs: for this study the body temperature data came from isotopes and the growth rate data from long-bone anatomy and histology (section 4 below). The key assumption, of course, surrounds the use of metabolic data from extant vertebrates to estimate dinosaur metabolism. This is especially critical given that metabolism is the major component of the energy budget of all extant vertebrates. However the physiological processes generating metabolic energy are common across vertebrates, including both the nearest relatives and direct descendants of dinosaurs. We can therefore be reasonably confident that the mass-dependency and temperature sensitivity of dinosaur metabolism can meaningfully be estimated from living taxa. The big unknown is the intensity (level) of dinosaur resting metabolism, which is precisely what this study explores.

Respiration dominates the energy budget (Figure A1), and so parameterisation of BMR and FMR is critical. The boundary conditions for a viable balanced energy budget were explored by parameterising BMR with data from mammals (upper bound, representing endothermy) and reptiles (lower bound, representing ectothermy). FMR and absolute metabolic scope were then estimated using data for a range of extant terrestrial vertebrates.

Basal (maintenance) metabolism, BMR, is usually estimated by a measure of resting metabolic rate. BMR typically exhibits a power law relationship with body mass $(\mathrm{Mb})$ and an exponential dependence on body temperature $(\mathrm{Tb})$. Inclusion of body temperature is important, as the influence of $\mathrm{Tb}$ on BMR is significant in both endotherms and ectotherms. Tb has traditionally been ignored in analyses of mammalian metabolism, presumably on the assumption that in mammals Tb exhibits a narrow range of values. In fact mammals show a range of $\mathrm{Tb}$ values $>10 \mathrm{~K}$ (Clarke and Rothery 2008) and the effect of $\mathrm{Tb}$ on endotherm metabolism is significant (Clarke et al. 2010).

The most appropriate statistical model for capturing the joint effects of $M b$ and Tb on BMR is thus:

$$
\operatorname{Ln} B M R=a+b_{1}(\operatorname{Ln} M b)+b_{2}(T b)
$$

BMR is in $\mathrm{mW}, M b$ is in $\mathrm{g}$, and $\mathrm{Tb}$ is ${ }^{\circ} \mathrm{C}$. The partial regression coefficient $b_{2}$ can be converted simply to a $\mathrm{Q}_{10}$ value: $\mathrm{Q}_{10}=\exp \left(b_{2} * 10\right)$.

The statistical model can be expanded to include non-linear effects of $M b$, and any interactions between $M b$ and $\mathrm{Tb}$, both of which are significant in mammals (Clarke et al. 2010). BMR is typically expressed in units of oxygen consumption $\left(\mathrm{ml} \mathrm{h}^{-1}\right)$, this being how metabolic rates are usually measured in the laboratory. These data were converted to SI units using the standard oxycalorific coefficient of $19.4 \mathrm{~J} \mathrm{ml}^{-1} \mathrm{O}_{2}$ gas (Brafield and Llewellyn 1982): an oxygen consumption of $1 \mathrm{ml} \mathrm{h}^{-1}$ thus equates to a rate of heat dissipation of $5.4 \mathrm{~mW}$.

BMR data for mammals. The mammal data and relationships were taken from Clarke et al. (2010). In mammals the scaling of BMR with $M b$ is significantly non-linear (Clarke et al. 2010); above $~ 150$ $\mathrm{g}$, however, the relationship is effectively linear with a scaling exponent $\left(b_{1}\right)$ of 0.751 There is a small but significant interaction between $M b$ and $\mathrm{Tb}$ (larger taxa tend to be warmer). 
BMR data for modern reptiles. Data for reptile resting metabolic rate (taken to be representative of basal metabolic rate, $B M R$ ) and body temperature $(T b)$ were taken from White et al. (2006). The taxonomy of the reptile $B M R$ data set was checked against the Reptile Database (www.reptiledatabase.org) to remove synonymies. The checked data set contained 483 records for 155 species. Because the variable replication across species can lead to biased estimates of parameters, the data were reduced by selecting one data point per species: where $\mathrm{n}=2$, data for the higher $T b$ was taken, where $\mathrm{n}>2$ the second highest $T b$ was used (because some studies of the thermal sensitivity of metabolism extend outside the normal range of $T b$ values experienced in the wild). This data set had data for 155 species. Preliminary analysis revealed six species with high standardised residuals $(</>$ 2), and these data were excluded from all subsequent statistical analyses.

The interaction term was non-significant $(p=0.297)$, indicating that the temperature sensitivity of $B M R$ does not vary with body size. The interaction term was therefore dropped from the model. In addition the quadratic term in $M b$ was not significant $(p=0.248)$; unlike mammals, in reptiles there is no indication of curvilinearity in the scaling of $B M R$ with $M b$.

Analysis with a General Linear Model (GLM) indicated significant variation in BMR across reptile families $\left(\mathrm{F}_{26,148}=5.13, p<0.001\right)$, with the pattern of variation in mean family BMR very similar to that reported by Andrews and Pough (1985). Some of these families were, however, represented by data for very few taxa. The GLM was therefore repeated at suborder level, and this revealed significant difference between snakes and lizards in the scaling of BMR $\left(\mathrm{F}_{1,148}=4.47, p=0.001\right)$. This result suggests that a relationship based on lizards alone might be the better model for exploring dinosaur energetics. This relationship was estimated for all species in Suborder Lacertilia (Sauria), but excluding three species with standardised residuals $\langle/>2$.

\begin{tabular}{|l|l|l|l|l|}
\hline & $\mathbf{n}$ & $\mathbf{b}_{\mathbf{1}}$ & $\mathbf{b}_{\mathbf{2}}$ & $\mathbf{Q}_{\mathbf{1 0}}$ \\
\hline All reptiles & 149 & 0.771 & 0.081 & 2.25 \\
\hline Lacertilia & 84 & 0.833 & 0.081 & 2.25 \\
\hline
\end{tabular}

For both the all-reptile and lizard relationships the partial regression coefficient $b_{2}$ is equivalent to an across-species $\mathrm{Q}_{10}$ of 2.25. The full reptile data set had 66 taxa where $B M R$ has been measured at more than one temperature, the range typically being between 5 and $15 \mathrm{~K} . \mathrm{Q}_{10}$ was calculated only where range $>8 \mathrm{~K}$, and the mean value for these 60 within-species $\mathrm{Q}_{10}$ values was 2.32 (SE 0.58).

Field metabolic rate in reptiles. Data for reptile Field Metabolic Rate, FMR, were taken from Nagy (2005). The statistical model fitted by linear regression was:

$$
\operatorname{Ln}(F M R)=a+b_{1} \cdot \operatorname{Ln}(M b)
$$

with $F M R$ in $\mathrm{mW}$ and $M b$ in $\mathrm{g}$. The model has no temperature term because $T b$ was unrecorded in most of the free-ranging reptiles whose FMR was measured. Whilst we can assume that the mitochondria generating the ATP that supports the metabolic scope have a similar temperature sensitivity to those supporting BMR, but without knowledge of mean daily $\mathrm{Tb}$ in those free-ranging reptiles for which isotope turnover data are available, we cannot apply a temperature correction. The model was fitted to data for all reptiles and for lizards only:

\begin{tabular}{|l|l|l|l|}
\hline & $\mathbf{n}$ & $\mathbf{b}_{\mathbf{1}}$ & SD \\
\hline All reptiles & 55 & 0.888 & 0.029 \\
\hline Lacertilia & 48 & 0.916 & 0.026 \\
\hline
\end{tabular}

The analyses suggest that the scaling exponent for FMR in reptiles $(\sim 0.89)$ is significantly greater than in endotherms (mammals 0.73, birds 0.68) (Clarke and Pörtner 2010). Speakman and Król (2010) have suggested that the mammal relationship may be biased by the mixture of terrestrial and aquatic species, and that in terrestrial mammals the scaling exponent for FMR is $\sim 0.65$. 
Metabolic scope. The metabolic scope captures the factor by which routine sustained activity exceeds basal metabolism. It thus integrates periods of rest, routine activity and occasional short-term bursts of maximum activity. A mean factorial scope (FMR/BMR) can be calculated from the individual scaling relationships for BMR and FMR. The difference in the scaling exponents for BMR and FMR mean that a factorial metabolic scope calculated in this way is size-dependent; when calculated over the body mass range $10^{2}-10^{4} \mathrm{~g}$, factorial scope in mammals is $3.3-4.2$, in birds 3.9 -4.6 and in reptiles 3.2-5.8 (Clarke and Pörtner 2010).

This is an important observation, for it indicates that the evolution of an endothermic metabolism has not resulted in a markedly increased factorial aerobic scope. It does, however, pose the intriguing question of what aspect of physiology or ecology sets the long-term (sustained) level of factorial aerobic scope. A number of suggestions were discussed by Hammond and Diamond (1997), including both intrinsic (internal) and external factors, but there is currently no clear answer to what sets the level of sustained factorial aerobic scope in vertebrates, though the broad similarity across reptiles, birds and mammals of diverse size and ecology suggests limitation by a fundamental physiological mechanism rather than an external factor such as food supply.

These generalised scopes do not, however, allow the analysis of variation in scope within reptiles or mammals. To do this, we need to calculate individual factorial scopes for those species where we have data for both $B M R$ and FMR. The mean value was 2.52 (SD 1.57, range $1.00-6.31, \mathrm{n}=17$ after removal of one outlier value of 0.22 ).

Field (sustained) aerobic scopes have also been calculated for 28 species of lizard from literature data (Christian et al. 1997). Christian et al. (1997) reported significant variation in factorial scope with family in lizards. This was confirmed by a reanalysis of their data $\left(\mathrm{F}_{8,27}=3.16, \mathrm{p}=0.019\right)$. The analysis remained significant when the ANOVA was confined to those five families with three or more species in the data set $\left(\mathrm{F}_{4,17}=4.03, \mathrm{p}=0.018\right)$. The (sub)families with the highest factorial aerobic scope were Phrynosomatinae (mean 3.14, SD 1.03, $\mathrm{n}=5$ ) and Varanidae (mean 3.30, SD $1.10, \mathrm{n}=5)$.

For the model, herbivores were assumed to have a factorial scope equivalent to the all-reptile mean (2.52), whereas carnivores were assumed to have a more active lifestyle, and their factorial scope was estimated by the mean value for varanids (3.30).

\section{4: Growth}

Mass to energy conversion factors for vertebrate tissue. A representative energy content of organic matter (ash-free dry tissue), based on analysis of 255 (229 species) aquatic invertebrates, is 23 $\mathrm{kJ} \mathrm{g}^{-1}$ (Brey et al. 1988). It is unlikely that the composition of organic matter in vertebrates is sufficiently different to invalidate the use of this value for dinosaurs. The mineral ash content of tissue is typically $\sim 10 \%$, so this equates to an energy content for dry tissue of $20.7 \mathrm{~kJ} \mathrm{~g}^{-1}$.

To produce an energy density for an entire vertebrate this figure needs to be corrected for the mass of the skeleton. There appear to be no data on the fraction of a reptile body occupied by the internal skeleton, but there are good data for mammals (Pitts and Bullard 1968). The overall mean value is 0.0977 (SD 0.017, $\mathrm{n}=40$ ), with no indication of variation with body size $(p>0.1)$. In the absence of data for reptiles, the mammal data have been used. The energy content per gram dry mass (DM) on a whole-animal (tissue plus skeleton) basis is thus $18.7 \mathrm{~kJ} \mathrm{~g}^{-1}$. Allowing for a typical vertebrate whole body water content of $70 \%$ (Schmidt-Nielsen 1975), this equates to a whole-animal (tissue plus skeleton) energy content on a fresh mass (FM) basis of $5.61 \mathrm{~kJ} \mathrm{~g}^{-1}$. This value was used in the model.

Growth rates of dinosaurs. Determining dinosaur growth rate requires knowledge of mass at age; unfortunately neither age nor mass is easy to estimate in dinosaurs. Most progress with determining 
dinosaur age has been made with microscopic examination of bone sections and the use of lines of arrested growth (LAGs) (Reid 1997). Difficulties with this are that not all species show LAGs, LAGs can vary in intensity and number between different bones in the same individual (Horner et al. 1999), and bone remodelling may mean that LAGs representing early growth are missing (Lee \& Werning, 2008). Despite these difficulties, skeletochronology remains the best technique for estimating age in dinosaurs.

Estimating dinosaur mass is particularly difficult, but critical for the determination of growth rate. Techniques include allometric relationships between limb-bone circumference and body mass in mammals and birds (Anderson et al. 1985), volume displacement of accurate models (Alexander 1989), scaled skeletal reconstructions (Paul 1997), allometric relationships between length and an estimate of mass from high order polynomial description of body outline integrated to provide an estimate of volume (Seebacher 2001), and a technique termed 'developmental mass extrapolation' (DME), which estimates mass for any size from the ratio of length cubed to adult length together with the adult body mass (Erickson et al. 2001). These various techniques give quite different estimates of adult body mass, sometimes for the same individual. For example estimates of the body mass of an adult Apatosaurus vary from an upper limit of 43 tons (Russell (1989), through 25 tons (Anderson et al. 1985) to 13-19 tons (Paul 1997), and the body mass of an adult Maiasaura has been estimated as $6000 \mathrm{~kg}$ (Dunham et al, 1989, citing Horner 1983), $1500 \mathrm{~kg}$ (Erickson et al. 2001, citing Horner et al. 2000) and $2500 \mathrm{~kg}$ (Paul 2010).

Mass-at-age data are then used to fit a growth model. A number of models can be fitted to such growth data, including von Bertalanffy, logistic and Gompertz. These differ in shape, and hence the point in the growth curve where growth rate is maximal. A typical example of a three-parameter logistic growth model fitted to mass-at-age data for a dinosaur is shown in Figure A2.

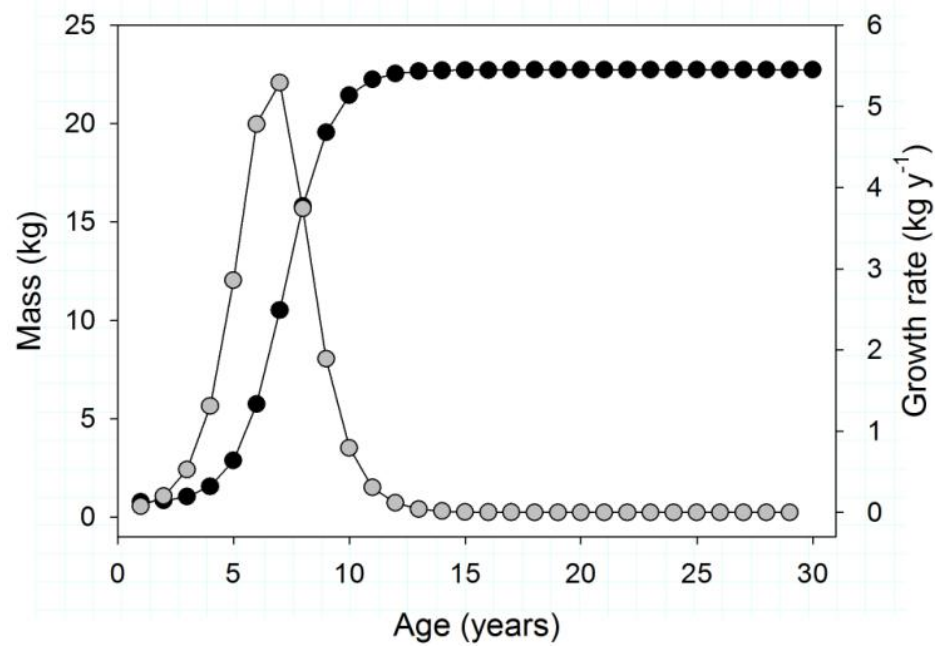

Figure A2. Modelled growth for the ceratopsian Psittacosaurus mogoliensis. Data plotted as body mass ( $\mathrm{kg}$, black symbols) and annual growth rate ( $\mathrm{kg} \mathrm{y}^{-1}$, grey symbols). Data and model taken from Erickson and Tumanova 2000. 
This shows the modelled growth for the ceratopsian Psittacosaurus monogoliensis; the growth model was constructed from data on age from bone histology and data on mass from long bone size. A growth model was then fitted to these data, and the plot shows the increase in body mass and the annual growth rate predicted by the model. The modelled growth for Psittacosaurus monogoliensis assumes an asymptotic body mass of $22.7 \mathrm{~kg}$, and predicts that the maximal life-time growth rate of $5.3 \mathrm{~kg} \mathrm{y}^{-1}$ occurs at an age of 7 years.

The most frequent models fit to dinosaur growth include adult (asymptotic) body mass as a fitted parameter, and the estimate of maximum growth rate varies with the estimated adult body mass (figure A3). For both a von Bertlanffy model and the three-parameter logistic model examples illustrated (Figure A3), a 10\% change in the estimate of adult body mass leads to a $10 \%$ change in the estimated maximum growth rate. The estimate of adult body mass is thus critical in assessing dinosaur growth rates; interestingly in many cases the adult (asymptotic) body size is greater than that of the largest individual sampled.

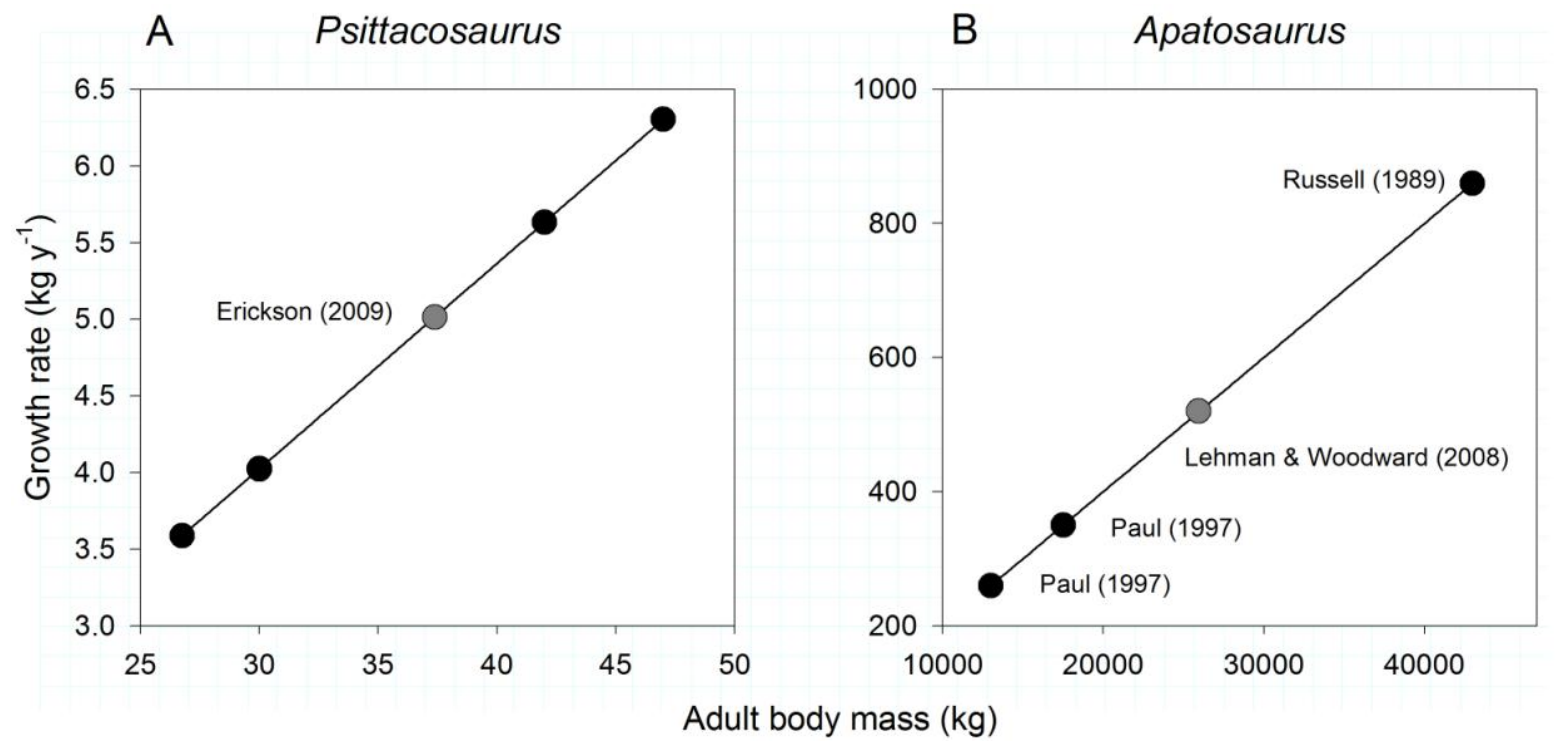

Figure A3. Relationship between estimated adult body mass and the consequent estimate of maximum annual growth rate in dinosaurs. A: Psittacosaurus lujiatunensis, showing adult $\mathrm{Mb}$ estimated by Erickson et al (2009) with maximum growth rates estimated from a three-parameter logistic model $(\mathrm{k}=0.55)$ for both larger and smaller adult sizes. B: Growth in Apatosaurus excelsus estimated for year 14 from a logistic growth model $(\mathrm{k}=0.045)$. From data in Figure 6 in Lehman \& Woodward (2008). Source of other adult body mass estimates shown.

The various models also differ in the point at which growth rate is maximum. Thus for a von Bertalanffy maximum growth rate is at the smallest size, in a three-parameter logistic it is half adult size $(\mathrm{Mb} / 2)$ and in a three-parameter Gompertz it is at $M b / \mathrm{e}$. By contrast, in extant reptiles maximum growth rate is typically at one-third maximum size (Case 1978). All of these considerations mean that available estimates of dinosaur maximum growth rate must be treated with care, but they are the only data we have. For estimating dinosaur growth rates, data were taken from all dinosaur growth literature known to the author.

Erickson et al. (2001) collated available data for dinosaur growth, fitting a four-parameter logistic model (though Shuvuuia and Maiasaura had only three data points, and Apatosaurus four). Data come from previous studies of Apatosaurus excelsus (Curry, 1999) and Psittacosaurus mongoliensis (Erickson \& Tumanova, 2000), combined with new analyses of histological growth series data taken from the literature for Syntarsus rhodesiensis (Chinsamy, 1990), Massospondylus carinatus 
(Chinsamy 1993) and Maiasaura peeblesorum (Horner et al. 2000), and added data for the small, highly derived maniraptorian theropod Shuvuuia deserti (Norell et al. 2001). The data used came from the solutions of the logistic growth equations presented in figure 2 of Erickson et al. (2001). Note that the model solutions for body mass at the point of inflection in the growth model (when growth rate is maximum) are all $>50 \%$ asymptotic body mass. Curry Rogers \& Erickson (2005) also concluded that Apatosaurus grew rapidly, though LAGs were present only late in ontogeny. Their estimate of maximum growth rate was identical to that of Curry (1999), reproduced in Erickson et al. (2001).

Erickson et al. (2004) examined growth in four species of tyrannosaur. Ages were assigned on basis of LAGs, and body mass estimated by developmental mass extrapolation. The growth model fitted was a four-parameter logistic. Again, the body mass at inflection was always $>50 \%$ asymptotic body mass. Bybee et al. (2006) estimated growth in three large theropods, using LAGs to age individuals in an ontogenetic series, and bone dimensions to estimate age. Data were fitted to a non-constrained three parameter logistic model, where mass at inflection is $50 \%$ adult mass.

Lehman (2007) estimated adult body mass in Chasmosaurus mariscalensis at $2520 \mathrm{~kg}$, and growth rate was estimated to be $31 \mathrm{~kg} \mathrm{y}^{-1}$ at a body mass of $750 \mathrm{~kg}$ from the regression relationship for extant reptile growth in Case (1978). This estimate thus starts from the assumption that Chasmosaurus grew similarly to living reptiles. Lehman (2007) also re-examined other dinosaur growth rate data, concluding that the age data for Massospondylus quoted by Chinsamy (1993) were underestimated. Lehman corrected the ages of the older specimens to obtain a more realistic looking growth curve. Chinsamy (1990) used LAGs to estimate the minimum age of specimens of Syntarsus as 3, 4 and 6 years; combined with body mass estimated from femur diameters given by Raath (1990) this yields a growth rate of $2.6 \mathrm{~kg} \mathrm{y}-1$. Varrichio (1993) estimated that Troodon required 3-5 years to reach an adult body mass of $50 \mathrm{~kg}$. The growth rate of Saurornitholestes can be estimated from LAGs in a single tibia (Reid 1993).

Lee \& Werning (2008) examined growth and sexual maturity in four tyrannosaurs. Age was estimated from LAGs, with correction for missing LAGs in older individuals. Non-linear regression was used to fit a three-parameter logistic model.

Lehman \& Woodward (2008) took a critical look at all available data for dinosaur growth rates. They concluded that growth rate estimates for Maiasaura and Apatosaurus from Erickson et al (2001) were overestimated and biologically unreasonable. Using minimum and maximum ages estimated from bone apposition rates for adult individuals together with adult body mass estimates from Paul (1997), average life-time growth rates for three Tendaguru sauropods were estimated. Body mass estimates from Paul (1997) tend to be lower than others, as allowance is made for bone pneumaticity. Using LAGs to determine age, and body mass estimated from bone dimensions, growth rate estimates were also made for other sauropods, based on growth models.

Erickson et al. (2009) estimated growth of Psittacosaurus lujiatunensis from 26 specimens, using LAGs to determine age and bone dimensions to estimate age, assuming Psittacosaurus was effectively bipedal. Hübner (2012) estimated growth in the basal ornithopod dinosaur Dysalotosaurus lettowvorbecki, using LAGs to determine age and the regression relationship of Anderson et al. (1985) to estimate body mass, and fitting a logistic growth curve.

The data are somewhat biased towards saurischians and herbivorous taxa; there are no suggestions of differences in growth rate between the main clades, or between dietary types $(p>0.1)$, but the data set is small and statistical power low. Because the use of a variable number of data points per species can lead to biased estimates of statistical parameters, only one growth rate estimate was used for each species. Where more than one estimate was available, the most recent was selected. 
Table A1. Growth rate data for dinosaurs. Body mass is shown for the adult and at the point of inflection of the growth curve, where growth rate is maximal. Growth rate data are either maximum rate derived from a fitted growth rate model, or a life-time average. Also shown, where known, are the number of data points used to fit the model and whether the data include a specimen at or close to the adult (asymptotic) body mass.

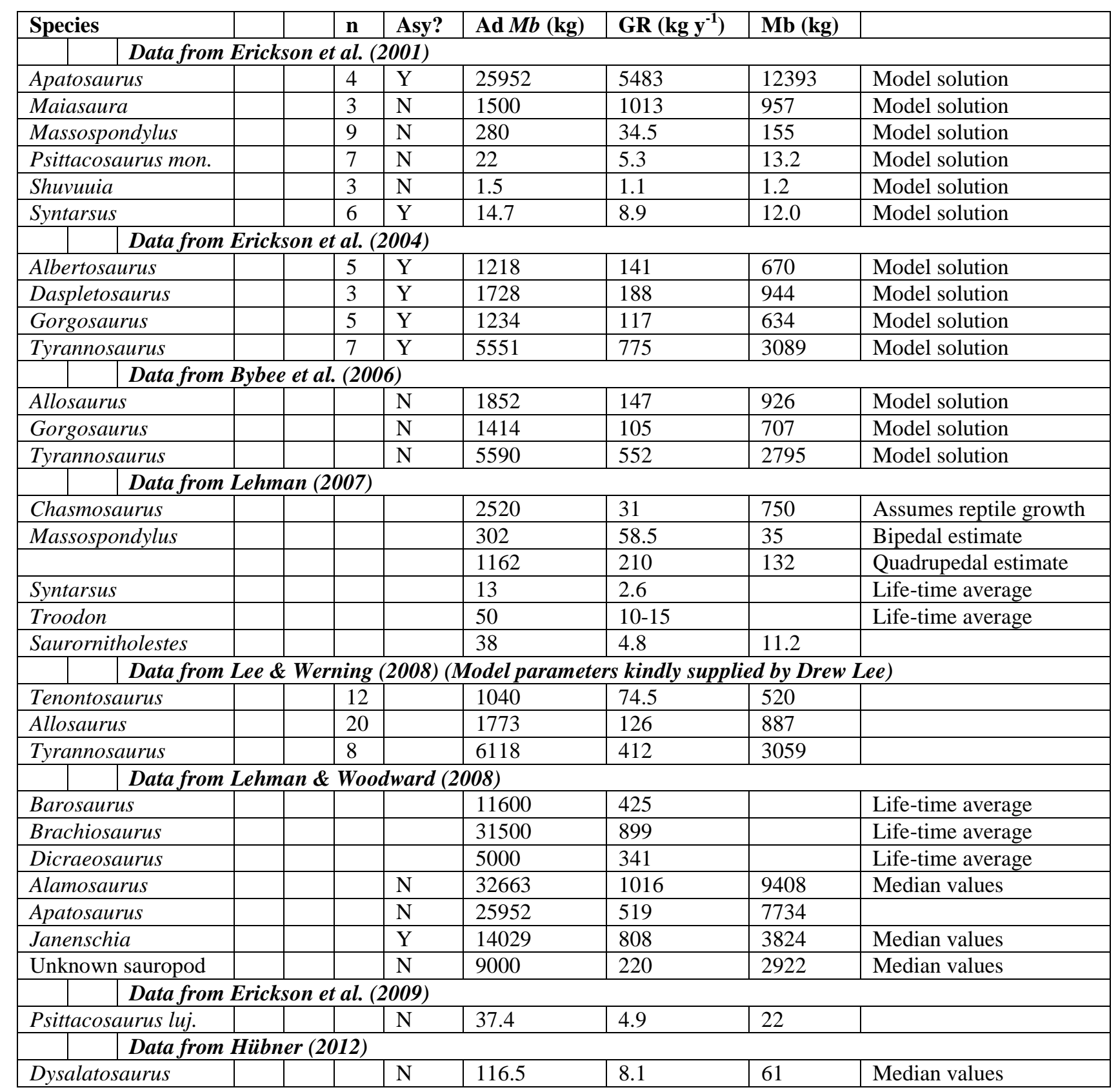

The data suggest that annual growth rate increases with asymptotic body size, as would be expected. There is no visual difference between data for maximum annual growth rate (estimated for the point of inflection in the growth curve) and growth rate averaged over the entire life span (Figure A4A). The data for Apatosaurus and Maiasaura (Erickson et al. 2001) deviate from the relationship for all other dinosaur growth rates, and are likely to be overestimates (Lehman 2007), whereas the data point for Chasmosaurus is likely to be an underestimate as it was derived on the assumption that growth in this species was similar to that of extant reptiles (Lehman 2007). 
A

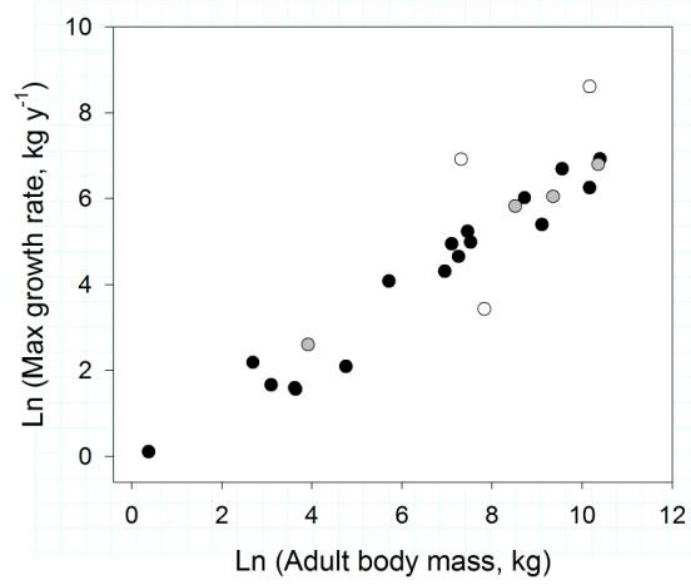

B

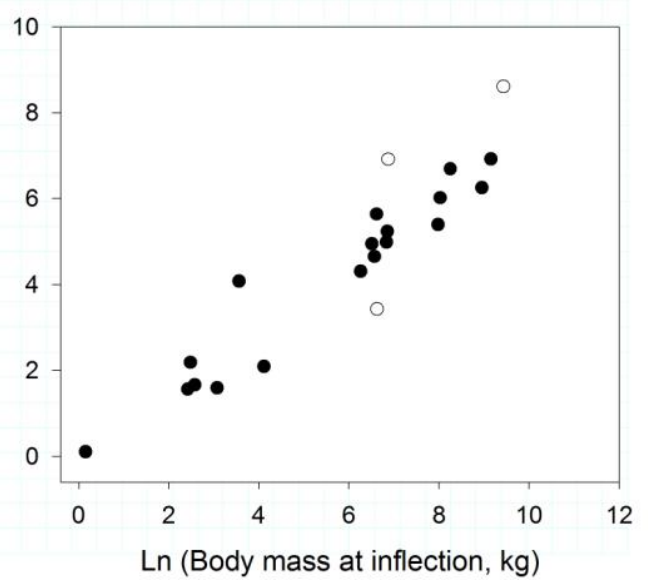

Figure A4. Growth rate and body mass in dinosaurs. A: Maximum annual growth rate $\left(\mathrm{kg} \mathrm{y}^{-1}\right)$ as a function of estimated adult body mass $(\mathrm{kg})$. Data are estimated for period of maximum growth (black symbols) or averaged over the entire life-span (grey symbols). B: Maximum annual growth rate $\left(\mathrm{kg} \mathrm{y}^{-1}\right)$ as a function of body mass $(\mathrm{kg})$ at point of inflection in the growth curve, when growth rate is typically maximal. In both panels, data for Apatasaurus and Maiasaura (Erickson et al. 2001) and Chasmosaurus (Lehman 2007) are shown as open (white) symbols.

For comparison with data for reptiles (Case 1978), and to ensure comparability of units across the different components of the model, growth rate data were converted to units of $\mathrm{g} \mathrm{d}^{-1}$. For dinosaurs it was assumed that growth took place for half the year (the length of the growing season was included as a variable in the model, and hence could be adjusted). The growth rate of dinosaurs was similar to, but slightly greater than, that reported for reptiles (Figure A5).

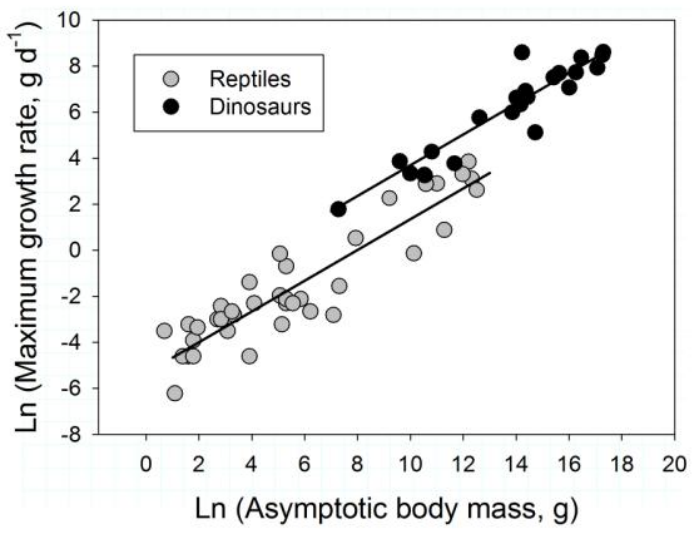

Figure A5. Daily growth rate in reptiles and dinosaurs. Reptile data from Case (1978), dinosaur annual growth data from Table A1, recalculated assuming growth takes place over half the year. Data show maximum growth rate $\left(\mathrm{g} \mathrm{d}^{-1}\right)$, and the body mass $(\mathrm{g})$ at which this growth rate occurs. The fitted lines are regression fits from a General Linear Model. Note that the dinosaur body mass data are here plotted as $\mathrm{g}$ (not $\mathrm{kg}$ ) to allow comparison with the reptile data.

Although the slope of the relationship fitted to reptiles alone (0.66) is lower than that for dinosaurs alone (0.75), analysis with a General Linear Model indicates no significant difference in the scaling exponent of daily growth rate with body mass in reptiles and dinosaurs $\left(\mathrm{F}_{1,57}=0.16, p=0.688\right)$. There was however a significant difference in elevation $\left(\mathrm{F}_{1,57}=4.06, p=0.001\right)$. This conclusion remained when mammals were included in the analysis $\left(\mathrm{F}_{2,210}=26.7, p<0.001\right)$. The robustness of this conclusion is, however, limited by the very different nature of the growth rate measurements in 
the two groups (maximum short-term growth rate observed in captive reptiles, and life-time growth model based on LAGs in long bones in dinosaurs), and the dinosaur data are sensitive to the assumed length of the annual growing period.

For modelling dinosaur growth rates, a relationship based on dinosaurs alone was used. The fitted model was:

$$
\operatorname{Ln} G R=b .(\operatorname{Ln} M b)+a
$$

Where GR is the maximum annual growth rate $\left(\mathrm{g} \mathrm{y}^{-1}\right)$ observed in the life-cycle, and $M b$ is the body mass $(\mathrm{g})$ at the point of inflection in the growth curve. This excludes 4 taxa where growth rate has been estimated by averaging over the entire life cycle and $M b$ at point of growth inflection is unknown. This is not the most useful relationship for use in the model, which is built around a time unit of 1 day and mass units of grams. To convert annual growth to daily growth, a growth season of 187 days (half a year of 374 days) was assumed. The different regression coefficients are:

\begin{tabular}{|l|l|l|l|l|l|}
\hline Mb(inf) & GR & b & SE(b) & a & (SE(a) \\
\hline $\mathrm{kg}$ & $\mathrm{kg} \mathrm{y}^{-1}$ & 0.75 & 0.07 & -0.06 & 0.43 \\
\hline $\mathrm{g}$ & $\mathrm{g} \mathrm{y}^{-1}$ & 0.75 & 0.07 & 3.32 & 0.89 \\
\hline $\mathrm{g}$ & $\mathrm{g} \mathrm{d}^{-1}(187)$ & 0.75 & 0.07 & -3.59 & 0.84 \\
\hline
\end{tabular}

Cost of growth. The synthesis of new tissue is not perfectly efficient; it incurs thermodynamic costs, usually referred to as the cost of growth (CoG) (Parry 1983). These costs are seen as respiratory losses and typically contribute significantly to the post-prandial rise in metabolism (the heat increment of feeding, HIF, or in older literature the specific dynamic action, SDA). The cost of growth represents the flow of entropy necessary to drive the synthesis reactions, and is a significant component of the metabolic scope (see Figure A1).

If we assume that the CoG forms a constant ratio to the energy content of the newly synthesised tissue, Ps (in other words the efficiency of synthesis remains constant), then:

$$
\mathrm{CoG}=c . \mathrm{Ps}
$$

Here $c$ is an efficiency factor which captures the respiratory cost of growth; it is dimensionless and has no units. Note that when $c$ is low, the efficiency of growth is high (that is, relatively less energy is dissipated in the synthesis of new tissue). A careful review of studies of the cost of growth in different groups of organisms suggested a net cost of growth, $c$, of 0.33 (Wieser 1994). This value was used in the model.

\section{5: Cost of transport}

Evaluating how much energy a dinosaur used in locomotor activity requires knowledge of two key factors. The first is the fraction of the available energy that is available for locomotion, and the second is the cost of that locomotion.

Estimating the power available for locomotor activity. For construction of an energy budget, the most useful of the measure of the activity cost of free-ranging reptiles is the fraction of the absolute metabolic scope that is used in locomotor activities, averaged over the daily cycle. Using data for 25 species of lizard (Christian et al. 1997), and selecting the largest value where more than one measurement is available for a species, the mean value is 57\% (SD 15.24). However if varanids are used to exemplify active predatory dinosaurs, then the mean is $73 \%(\mathrm{SD} 8.65, \mathrm{n}=5)$. Given the high 
variance in these data, rounded values were used in the model: $60 \%$ for herbivores and $75 \%$ for carnivores.

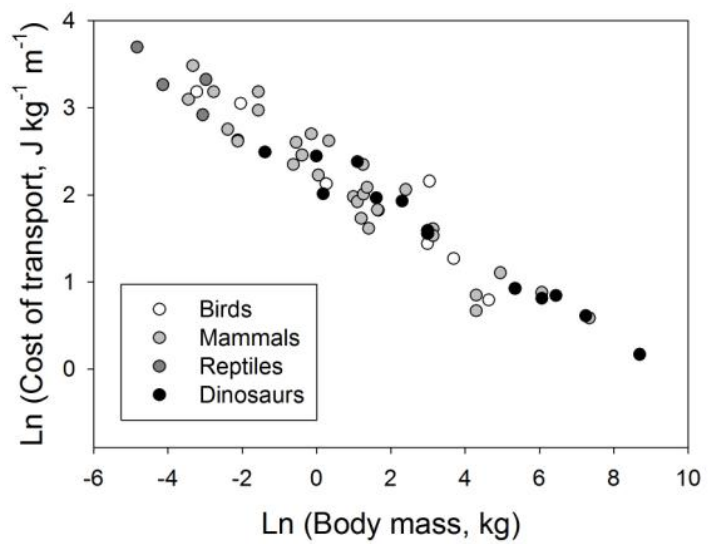

Figure A6. The cost of transport as a function of body mass in terrestrial vertebrates. Data for birds, mammals and reptiles are empirical, data for dinosaurs were estimated from a biomechanical model. All data from Pontzer (2007) and Pontzer et al. (2009).

Cost of transport for reptiles. The biomechanical cost of transport (CoT: $\left.\mathrm{J} \mathrm{kg}^{-1} \mathrm{~m}^{-1}\right)$ is strongly and inversely dependent on $M b$. Pontzer (2007) developed a model that predicts CoT from biomechanics (specifically the effective limb length). This model predicts the empirical data very well and can be used to predict the CoT for dinosaurs (Pontzer et al. 2009). In Figure A6, the data for birds (terrestrial locomotion only), non-aquatic mammals and reptiles are the empirical data used to generate the allometric relationship; the data for dinosaurs are predicted from the relationship on the basis of estimated body mass.

The model predicts a cost of locomotion for dinosaurs that fits the general relationship for terrestrial locomotion in vertebrates (Figure A5), and this model was used to predict the cost of locomotion in dinosaurs.

\section{6: Constructing the energy budget}

The model was constructed for actively growing sub-adult dinosaurs, with $M b$ ranging from $20 \mathrm{~g}$ to 65 tonnes and $T b$ ranging from 15 to $40^{\circ} \mathrm{C}$. Herbivores and carnivores were assumed to have slightly different energetics. Carnivores were modelled as active predators, using energetic variables and relationships taken from varanid lizards and assuming an absorption efficiency of $85 \%$. Herbivores were assumed to be better approximated by the all-reptile relationships, and the absorption efficiency was assumed to be $50 \%$.

A balanced budget was then calculated using a time period of one day ( 24 hours). This time-period is intermediate between the measurement periods typical for basal metabolism (hours) and growth (days to years); it is also long enough to smooth the short-term variations in total energy demand that characterise day to day existence. The algorithm was:

1. BMR was estimated from $M b$ and $T b$, using the empirical relationship for lizards (carnivores) or all reptiles (herbivores).

2. Absolute metabolic scope was estimated using the all-reptile value for factorial scope (2.4) for herbivorous taxa, and the varanid factorial scope (3.3) for carnivores. 
3. Growth rate was estimated from the relationship between maximum growth rate and body mass at inflection derived for dinosaur taxa. Growth was assumed to be seasonal, with annual growth taking place over half the year (187 days). The cost of growth was assumed to be 0.33 .

4. Excretory losses were estimated as $5 \%$ BMR, based on data for mammals (Brafield and Llewellyn 1982).

5. Total energy requirement was estimated by summing energy sequestered in new tissue, excretory losses and field metabolic costs.

6. Total food consumption was estimated by correcting for absorption efficiency; this value was then used to estimate turnover number (see below).

7. Absolute metabolic scope was assumed to comprise three fractions: locomotor costs $(60 \%$ in herbivores, $75 \%$ in active predators), cost of growth, and other non-locomotor costs.

8. Average distance travelled per day was estimated from the cost of, and the energy available for, locomotion from the absolute aerobic scope.

All empirical relationships were fitted statistically with Minitab; the model was run in MatLab.

Validation. There are two important questions in assessing the outcome of an energy budget model: is the model internally consistent, and does the budget balance? Whilst the model was parameterised with growth data from dinosaurs and metabolic data from living reptiles (ectothermic dinosaurs) and mammals (endothermic dinosaurs), the balance and internal consistency are assessed using general principles that apply to all vertebrate energetics.

A critical question is whether parameterisation with data from extant reptiles allows sufficient metabolic scope to fuel the cost of growth $(\mathrm{CoG})$, whilst still allowing sufficient power for activity $(\mathrm{Ra})$ and non-locomotor metabolic costs $(\mathrm{Rm})$. The model suggests that at large sizes, the cost of growth $(\mathrm{CoG})$ requires a small fraction of the metabolic scope $(<10 \%)$, but this fraction is greater at smaller sizes. The CoG utilises more of the scope in herbivores because their absolute scope is smaller than in carnivores. However in carnivores modelled as varanid lizards the fraction of the scope required for locomotor activity is assumed to be $75 \%$, and so only a small fraction is left for non-locomotor metabolic activities. Currently we lack data on extant lizards to assess whether this is sufficient, but on present knowledge the model suggests a viable internal balance when parameterised with data from extant reptiles.

The overall energy flux through an organism is best expressed as a turnover number, this being the fraction of body energy (or carbon) that is turned over per unit time (here per day). The turnover numbers for ectothermic dinosaurs predicted from the energetics model are typically slightly greater than observed in living reptiles (Farlow 1976). This is to be expected, given the generally higher $T b$ values and faster growth rates in dinosaurs. These faster growth rates, however, utilise only a small fraction of the non-locomotor aerobic scope, typically less than $15 \%$ in herbivores of body mass 10 $\mathrm{kg}$, and less than $10 \%$ in similarly sized carnivores. The turnover numbers for dinosaurs modelled as endotherms are slightly lower than observed in extant mammals (Farlow 1976). Again this is as expected, given the slightly lower daily growth rates in dinosaurs compared with mammals.

Sensitivity analysis. The MatLab model was analysed for sensitivity by varying each parameter in the model sequentially by $+10 \%$ and $-10 \%$, whilst holding all other parameters constant, and examining the change in estimated total energy demand. The results are summarised in Table A2. 
Table A2. Sensitivity analysis of the dinosaur energetics model. The data are the change (absolute deviation, in $\%$ of original value) in total energy demand for a $10 \%$ change in each model parameter. $\mathrm{H}$ : herbivore, C: carnivore.

\begin{tabular}{|l|l|c|c|}
\hline \multirow{2}{*}{ Parameter } & & \multicolumn{2}{c|}{ Change in total energy demand (\%) } \\
\cline { 3 - 4 } & & $\mathbf{+ 1 0 \%}$ & $\mathbf{- 1 0 \%}$ \\
\hline $\mathrm{b}_{1}$ & Mass scaling forBMR & 158 & 61 \\
\hline $\mathrm{b}_{2}$ & Temperature scaling of BMR & 32 & 24 \\
\hline $\mathrm{a}_{1}$ & Intercept for BMR & 20 & 25 \\
\hline Season & Length of growing season & 9 & 11 \\
\hline Scope $(\mathrm{H})$ & Factorial scope $(\mathrm{H})$ & 10 & 10 \\
\hline $\mathrm{AE} \%(\mathrm{H})$ & Absorption efficiency $(\mathrm{H})$ & 9 & 11 \\
\hline Scope $(\mathrm{C})$ & Factorial scope $(\mathrm{C})$ & 9 & 9 \\
\hline $\mathrm{AE} \%(\mathrm{C})$ & Absorption efficiency $(\mathrm{C})$ & 9 & 11 \\
\hline $\mathrm{b}_{3}$ & Mass scaling for growth & 7 & 3 \\
\hline $\mathrm{a}_{2}$ & Intercept for growth & 1 & 1 \\
\hline
\end{tabular}

The sensitivity analysis shows clearly that the largest influence on total energy demand of dinosaurs comes from the relationship between $B M R, T b$ and $M b$, with $M b$ having a far greater influence than $T b$. Season, factorial scope and assimilation efficiency had a modest influence, and the growth rate scaling relationship had very little influence. This is perhaps unsurprising, given that $B M R$ dominates the energy budget of ectotherms.

\section{Literature cited}

Anderson, J. F., A. Hall-Martin, and D. A. Russell. 1985. Long-bone circumference and weight in mammals, birds and dinosaurs. Journal of Zoology, London 207:53-61.

Andrews, R. A., and F. H. Pough. 1985. Metabolism of squamate reptiles: allometric and ecological relationships. Physiological Zoology 58:214-231.

Blaxter, K. L. 1989, Energy metabolism in animals and man. Cambridge, Cambridge University Press.

Brafield, A. E., and M. J. Llewellyn. 1982, Animal energetics: Teriary Level Biology. Glasgow \& London, Blackie.

Brey, T., H. Rumohr, and S. Ankar. 1988. The energy content of macrobenthic invertebrates: general conversion factors from weight to energy. Journal of Experimental Marine Biology and Ecology 117:271-278.

Brown, J. H., J. F. Gillooly, A. P. Allen, V. M. Savage, and G. B. West. 2004. Toward a metabolic theory of ecology. Ecology 85:1771-1789.

Bybee, P. J., A. H. Lee, and E.-T. Lamm. 2006. Sizing the Jurassic theropod dinosaur Allosaurus: assessing growth strategy and evolution of ontogenetic scaling of limbs. Journal of Morphology 267:347-359.

Case, T. J. 1978. On the evolution and adaptive significance of postnatal growth rates in the terrestrial vertebrates. Quarterly Review of Biology 53:243-282.

Chinsamy, A. 1990. Physiological implications of the bone histology of Syntarsus rhodesiensis (Saurischia: Theropoda). Palaeontologia Africana 27:77-82.

Christian, K. A., R. V. Baudinette, and Y. Pamula. 1997. Energetic costs of activity by lizards in the field. Functional Ecology 11:392-397.

Christian, K. A., and S. Waldschmidt. 1984. The relationship between lizard home range and body size: a reanalysis of the data. Herpetologica 40:68-75.

Clarke, A. 1987. Temperature, latitude and reproductive effort. Marine Ecology Progress Series 38:89-99.

Clarke, A., and H. O. Pörtner. 2010. Temperature, metabolic power and the evolution of endothermy. Biological Reviews 85:703-727.

Clarke, A., and P. Rothery. 2008. Scaling of body temperature in birds and mammals. Functional Ecology 22:58-67.

Clarke, A., P. Rothery, and N. J. B. Isaac. 2010. Scaling of basal metabolic rate with body mass and temperature in mammals. Journal of Animal Ecology 79:610-619.

Curry, K. A. 1999. Ontogenetic history of Apatosaurus (Dinosauria: Sauropoda); new insights on growth rates and longevity. Journal of Vertebrate Paleontology 19:654-665. 
Curry Rogers, K., and G. M. Erickson. 2005. Sauropod histology: microscopic views on the lives of giants, Pages 303-326 in K. A. Curry Rogers, and J. A. Wilson, eds. The sauropods: evolution and paleobiology. Berkeley, California, University of California Press.

Dunham, A. E., K. L. Overall, W. P. Porter, and C. A. Forster. 1989. Implications of ecological energetics and biophysical and developmental constraints for life-history variation in dinosaurs, Pages 1-19 in J. O. Farlow, ed. Paleobiology of the dinosaurs. Geological Society of America Special Paper 238. Boulder, Colorado, Geological Society of America.

Erickson, G. M., P. J. Mackovicky, P. J. Currie, M. A. Norell, S. A. Yerby, and C. A. Brochu. 2004. Gigantism and comparative life-history parameters of tyrannosaurid dinosaurs. Nature 430:772-775.

Erickson, G. M., P. J. Makovicky, B. D. Inouye, C.-F. Zhou, and K.-Q. Gao. 2009. A life table for Psittacosaurus lujiatunensis: initial insights into ornithischian dinosaur population biology. The Anatomical Record 292:1514-1521.

Erickson, G. M., K. C. Rogers, and S. A. Yerby. 2001. Dinosaurian growth patterns and rapid avian growth rates. Nature 412:429-433.

Erickson, G. M., and T. A. Tumanova. 2000. Growth curve of Psittacosaurus mongoliensis Osborn (Ceratopsia: Psittacoridae) inferred from long bone histology. Zoological Journal of the Linnaean Society 130:551566.

Farlow, J. O. 1976. A consideration of the trophic dynamics of a late Cretaceous large-dinosaur community (Oldman Formation). Ecology 57:841-857.

Gillooly, J. F., A. P. Allen, and E. L. Charnov. 2006. Dinosaur fossils predict body temperatures. PLoS Biology 4:e248 (1467-1469).

Gillooly, J. F., J. H. Brown, G. B. West, V. M. Savage, and E. L. Charnov. 2001. Effects of size and temperature on metabolic rate. Science 293:2248-2251.

Hammond, K. A., and J. Diamond. 1997. Maximal sustained energy budgets in humans and animals. Nature 386:457-462.

Horner, J. R. 1983. Cranial osteology and morphology of the type specimen of Maiasaura peeblesorum (Ornithischia; Hadrosauridae), with a discussion of its phylogenetic position. Journal of Vertebrate Paleontology 3:29-38.

Horner, J. R., A. de Ricqlès, and K. Padian. 1999. Variation in dinosaur skeletochronology indicators: implications for age assessment and physiology. Paleobiology 25:295-304.

- 2000. Long bone histology of the hadrosaurid dinosaur Maiasaura peeblesorum: growth dynamics and physiology based on an ontogenetic series of skeletal elements. Journal of Vertebrate Paleontology 20:115-201.

Hou, C., W. Zuo, M. E. Moses, W. H. Woodruff, J. H. Brown, and G. B. West. 2008. Energy uptake and allocation during ontogeny. Science 322:736-739.

Hübner, T. R. 2012. Bone histology in Dysalotosaurus lettowvorbecki (Ornithischia: Iguanodontia) - variation, growth, and implications. PLoS One 7:e29958.

Hulbert, A. J., and P. L. Else. 2000. Mechanisms underlying the cost of living in animals. Annual Review of Physiology 62:207-235.

—. 2004. Basal metabolic rate: history, composition, regulation, and usefulness. Physiological and Biochemical Zoology 77:869-876.

Kearney, M. 2012. Metabolic theory, life history and the distribution of a terrestrial ectotherm. Functional Ecology 26:167-179.

Lee, A. H., and S. Werning. 2008. Sexual maturity in growing dinosaurs does not fit reptilian growth models. Proceedings of the National Academy of Sciences of the United States of America 105:582-587.

Lehman, T. M. 2007. Growth and population age structure in the horned dinosaur Chasmosaurus, Pages 259317 in K. Carpenter, ed. Horns and beaks: ceratopsian and ornithopod dinosaurs. Life of the past. Bloomington and Indianapolis, Indiana University Press.

Lehman, T. M., and H. N. Woodward. 2008. Modeling growth rates for sauropod dinosaurs. Paleobiology 34:264-281.

Milligan, L. P., and M. Summers. 1986. The biological basis of maintenance and its relevance to assessing responses to nutrients. Proceedings of the Nutrition Society 45:185-193.

Moses, M. E., C. Hou, W. H. Woodruff, G. B. West, J. C. Nekola, W. Zuo, and J. H. Brown. 2008. Revisiting a model of ontogenetic growth: estimating model parameters from theory and data. American Naturalist 171:632-645.

Nagy, K. A. 2005. Field metabolic rate and body size. Journal of Experimental Biology 208:1621-1625.

Norell, M. A., J. M. Clark, and P. J. Makovicky. 2001. Phylogenetic relationships among coelurosaurian theropods, Pages 49-67 in J. Gauthier, and L. F. Gall, eds. New perspectives on the origin and early evolution of birds. Proceedings of the international symposium in honor of John H Ostrom. Special Publication of the Peabody Museum of Natural History. New Haven, Special Publication of the 
Peabody Museum of Natural History.

Parry, G. D. 1983. The influence of the cost of growth on ectotherm metabolism. Journal of Theoretical Biology 101:453-477.

Paul, G. S. 1997. Dinosaur models: the good, the bad, and using them to estimate the mass of dinosaurs, Pages 129-154 in D. L. Wolberg, E. Stump, and G. D. Rosenberg, eds. DinoFest international; proceedings of a symposium held at Arizona State University. Philadelphia, Academy of Natural Sciences.

—. 2010, Dinosaurs: a field guide. London, A \& C Black.

Peterson, C. C., K. A. Nagy, and J. Diamond. 1990. Sustained metabolic scope. Proceedings of the National Academy of Sciences of the United States of America 87:2324-2328.

Petrusewicz, K., and A. Macfadyen. 1970, Productivity of terrestrial animals: principles and methods: International Biological Programme Handbook, v. No 13. Oxford, Blackwell Scientific Publications.

Pitts, G. C., and T. R. Bullard. 1968. Some interspecific aspects of body composition in mammals, Pages 45-70 Body composition in animals and man, National Academy of Science, Washington, D.C., Publication 1598.

Pontzer, H. 2007. Effective limb length and the scaling of locomotor cost in terrestrial animals. Journal of Experimental Biology 210:1752-1761.

Pontzer, H., V. Allen, and J. R. Hutchinson. 2009. Biomechanics of running indicates endothermy in bipedal dinosaurs. PLoS ONE 4:e7783.

Raath, M. A. 1990. Morphological variation in small theropods and its meaning in systematics, Pages 91-105 in K. Carpenter, and P. J. Currie, eds. Dinosaur systematics: perspectives and approaches. Cambridge, Cambridge University Press.

Reid, R. E. H. 1993. Apparent zonation and slowed late growth in a small Cretaceous theropod. Modern Geology 18:391-406.

—. 1997. How dinosaurs grew, Pages 403-413 in J. O. Farlow, and M. K. Brett-Surman, eds. The complete dinosaur. Bloomington, Indiana University Press.

Russell, D. A. 1989, An odyssey in time: the dinosaurs of North America. Minocqua, WI and Ottawa, Northwood Press.

Schmidt-Nielsen, K. 1975, Animal physiology: adaptation and environment. Cambridge, Cambridge University Press.

Seebacher, F. 2001. A new method to calculate allometric length-mass relationships of dinosaurs. Journal of Vertebrate Paleontology 21:51-60.

Sousa, T., T. Domingos, and S. A. L. M. Kooijman. 2008. From empirical patterns to theory: a formal metabolic theory of life. Philosophical Transactions of the Royal Society of London, Series B 363:2453-2464.

Sousa, T., T. Domingos, J.-C. Poggiale, and S. A. L. M. Kooijman. 2010. Dynamic energy budget theory restores coherence in biology. Philosophical Transactions of the Royal Society of London, Series B 365:3413-3428.

Speakman, J. R., and E. Król. 2010. Maximal heat dissipation capacity and hyperthermia risk: neglected key factors in the ecology of endotherms. Journal of Animal Ecology 79:726-746.

Varricchio, D. J. 1993. Bone microstructure of the Upper Cretaceous theropod dinosaur Troodon formosus. Journal of Vertebrate Paleontology 13:99-104.

West, G. B., J. H. Brown, and B. J. Enquist. 1997. A general model for the origin of allometric scaling laws in biology. Science 276:122-126.

-. 2001. A general model for ontogenetic growth. Nature 413:628-631.

White, C. R., N. F. Phillips, and R. S. Seymour. 2006. The scaling and temperature dependence of vertebrate metabolism. Biology Letters 2:125-127.

Wieser, W. 1994. Cost of growth in cells and organisms: general rules and comparative aspects. Biological Reviews 68:1-33. 